Running head: The Netherlands, interpersonal perspective

\title{
An interpersonal perspective on Classroom Management in Secondary Classrooms in the Netherlands
}

\author{
Theo Wubbels, Mieke Brekelmans, Perry den Brok and Jan van Tartwijk \\ Utrecht University, Utrecht, The Netherlands
}

To be published in the Handbook of Classroom Management: Research, Practice, and Contemporary Issues, Lawrence Erlbaum Associates

\section{Introduction}

This chapter reports on results of research from 25-year program of studies investigating teacher-student interpersonal relationships in secondary classrooms. This research focuses on the role of the teacher and builds a knowledge base about managing classrooms to create effective learning environments. Starting in the Netherlands, this line of research now has developed to many other countries such as Australia, Canada, Israel, Slovenia, Turkey, Korea, Taiwan, Singapore and the US. In this chapter, we will focus on Dutch research, referring when useful to the research in other countries.

We begin this chapter with a discussion of the multiple perspectives that can be used to analyze teaching and then describe the communicative systems approach, the central element of the interpersonal perspective that is the focus of this chapter. We then turn to other element, the Model for Interpersonal Teacher Behavior and measurement instruments developed to map teacher interpersonal behavior. The remainder of the chapter reviews studies on diverse issues covering the development of interpersonal teacher behavior during the teaching career, problems of beginning and experienced teachers including the non-verbal behavior and the spatial position of the teacher in the class, teacher interpersonal relations and student outcomes, differences between teacher and student perceptions of the relationship, and finally interventions to improve relationships in class.

\section{Multiple perspectives on teaching}

Classroom teaching is a complex task in a complex environment. Usually a (Dutch) secondary school teacher is in a modest-sized room with between 20 and 40 students. Many factors including emotional, cultural, interpersonal, and environmental issues influence the teacher, the students, and what occurs in class (Shuell, 1996). To reach their aims in this complex situation teachers have to fulfill many functions often at the same time (e.g. motivating, instructing, and organizing) (see Doyle in this volume XXXX). To grasp this complexity, some researchers 
distinguish between different types of teaching acts such as classroom management or instructional behaviors (e.g., Brophy \& Good, 1986; Creemers, 1994; Lee, 1995). Rather than distinguishing between different types of teaching acts we want to look at teaching from different perspectives. Although these perspectives are different, often there is also overlap.

Consider a classroom in which a teacher is lecturing. From the subject matter perspective, one can analyze whether or not the content presented is correct or what content has been selected by the teacher, what concepts are being used. One can also study the effects of lecturing on the teacher's relationship with the students: does this teacher engage them, do they see him or her as someone who really understands their problems and needs? We define this as part of the interpersonal perspective. When analyzing the type of learning activities the teacher elicits, for example, we ask: Do students have to rehearse information, or do they have to organize characteristics or objects? We define this as the learning activities perspective. Yet an alternative focus is the moral perspective that considers the values communicated by the teacher. For instance, does the teacher show a commitment to democratic values? In a classroom management perspective, the contribution of teaching is studied to create a productive working environment. A variety of perspectives can thus be employed consecutively to study one teaching act, or a series of acts. The analyses of the U.S. Secretary of Education's publicly broadcasted lesson about Lincoln's paper on the constitution show, for example, the perspective of instructional effectiveness, a discourse perspective, a moral perspective, and a gender perspective (see the analysis of the Bennett tape, Morine-Dershimer, 1986).

As will be clear from these examples, perspectives can be distinguished from each other, but some also overlap. In particular, the classroom management and interpersonal perspectives overlap. In the research reviewed in this chapter, teaching has been studied from an interpersonal perspective. The interpersonal perspective describes and analyzes teaching in terms of the relationship between teacher and students. The analysis of the teacher role in this perspective contributes to our understanding of the teacher's classroom management. Two elements are central to this perspective: the communicative systems approach and a model to describe teacher behavior. We will discuss these two elements before turning to research results.

\section{The communicative systems approach}

To analyze teachers' contributions to relationships with students their behavior can be considered a form of communication. Three definitions of communicative behavior can be distinguished. In the first, behavior is called communication only if the sender and receiver perceive the same meaning. A second definition considers behavior to be communicative 
whenever the sender consciously and purposefully intends to influence someone else. We adopt the third and most comprehensive definition that considers as communication every behavior that someone displays in the presence of someone else. This choice is an element of the so-called 'systems approach' (Watzlawick, Beavin, \& Jackson 1967), that assumes that one cannot not communicate when in the presence of someone else, whatever a person's intentions are, the others will infer meaning from this behavior. For example, if teachers ignore students' questions because they do not hear them, then students (e.g., might infer that the teacher is too busy, that the teacher thinks that the students are too dull to understand, or that the teacher considers the questions to be impertinent). The message that students take from the teacher's inattention can often be different from that which the teacher intends.

In the systems approach to communication, the focus is on the effects of someone's actions on the other. It focuses on the pragmatic aspects, that is pragmatic as to of the effects on the other involved. We will now discuss several features of this approach that include two aspects and three levels of communication, the cyclical character of exchanges of communication, and the frequent disagreement about who is responsible for problems in communication. We conclude with an emphasis on perceptions following from this pragmatic aspect.

\section{Content and relationship}

According to the systems approach, every form of communication has a content and a relation aspect (Watzlawick et al., 1967), also referred to as the report and the command aspects of behavior (cf. La France \& Mayo, 1978). The content conveys information or description; the relational aspect carries instructions about how to interpret the content. Therefore, in a class, teacher and students often relate in ways that are outside the subject matter (content).

\section{Message, interaction and pattern}

Within the systems approach to communication, three levels of communication are distinguished. The lowest level consists of one single unit of behavior, the message level, with a content and relation aspect. For instance, the words, 'I want to help you to learn,' can be combined with either a smile or a frown. In the latter case, the interpersonal aspect of this communication may be perceived as: 'I think you are too stupid to learn' (Marshall \& Weinstein, 1986). A series of exchanged interpersonal messages is called an interaction, the second communicative level. An example of an interaction occurs when the teacher asks a specific student a question, and the student ignores the teacher. The teacher then asks another student the same question, without paying any further attention to the first student. The students in the class 
will perhaps understand from this event that the teacher wants to avoid a confrontation with the first student. Therefore, they may expect that they can determine their own activities without a very high risk of confronting the teacher. When after a while, the exchange of interpersonal messages becomes cyclic, and when action and reaction (or cause and effect) are hard to distinguish, then recurrent patterns can be identified in the exchange of messages. This is the most extended level of communication, the pattern level. The longer the students and the teacher interact the more their behavior will become predictable, since their mutual expectations get confirmed and reconfirmed, and thus these will be regarded as the norm and form a stable basis for reactions.

\section{Circularity}

The notion of circularity in the systems approach to communication highlights that someone's behavior influences someone else and that the behavior of the second person on his or her in turn influences the first. Watzlawick and his colleagues (1967) describe vividly how patterns in relationships may evolve and be sustained: for example the friendly behavior of one person communicating with someone else may evoke friendly behavior from the other, thus creating a pleasant relationship. On the other hand, criticism and angriness may evoke the same behavior from the other, creating an escalating relationship of mutual distrust, hostility, or aggression (see Wubbels, Créton, \& Holvast, 1988; Lapointe, 2003).

Interchanges in series of messages can be either symmetrical or complementary, depending on whether they are based on equality or difference. In the case of symmetry, the behavior of the one is followed by the same kind of behavior from the other. In the complementary case, the communicating sides show opposite behavior. The teacher-student relationship with respect to the aspect of power, is structurally a complementary relationship. The teacher is the expert, the grown-up, the elder, the one who is responsible; the student on the other hand has still to learn everything, is a child to whom little responsibility is assigned in most cases. The teacher teaches, assesses and punishes; the student is taught, is assessed and is punished.

In a structural complementary relationship, both types of interchanges in series of messages (symmetrical and complementary) can, and usually will, occur. For example, a teacher's respect and caring for students can evoke and intensify students' respect and caring for the teacher, a positive symmetrical interchange. Negative symmetrical escalation, in fact a form of pathology, occurs, for example, when a teacher answers student disruptive behavior with severe punishment that may provoke aggressive behavior of the student, even more harsh punishment etc. 
In case of complementary communication, rigidity can evolve: the roles of teacher and student can intensify such that students do not take any initiative. The positions of teacher and students in the complementary relationship join with each other, leaving the possibility that complementary behaviors intensify, so that the differences become greater and greater and students start to behave more immaturely, less independently, and more irresponsibly.

\section{Who is to blame}

Participants in the communication process continually exchange messages. This process may be interpreted as an uninterrupted sequence of interchanges in which cause and effect cannot be distinguished. Watzlawick et al. (1967, page 54) argue that participants in the interaction, however, always introduce causation or order in the sequence of events. People who are communicating name messages in terms of stimulus and response; one message is considered to be the cause of the other. Teacher and students may have entirely different opinions about which behavior is cause and which is effect. They see the behavior of (the) other(s) as cause of and justification for their own behavior (e.g., the other is to blame). In most disorderly lessons, when the behavior of the teacher or students is unreasonable, unreasonable behavior may escalate. For instance, when students capitalize on every opportunity to create disturbances, or when the teacher punishes the wrong students, there may be general agreement about if and how certain events have taken place, but disagreement about which behavior is cause and which is result, and thus who was to blame. Both sides may feel that the other is the one who started the exchange.

If both sides show little understanding of each other's behavior, their interaction often has an escalating character. Teacher and students may find themselves in a vicious circle in which they intensify each other's behavior. The solution to this problem cannot be found by looking for who is right. The very assumption that such a sequence of messages has a "beginning" is erroneous according to Watzlawick et al. (1967). Only by changing one's own behavior can one change the behavior of the other person, and thus break the destructive spiral.

\section{Perceptions}

The pragmatic orientation of the communicative systems approach (i.e., what is the effect of communication on someone else) has evolved in our conceptualization of the interpersonal perspective as we focused on the perceptions of students of the behavior of their teachers. We

have focused not so much on the stated intentions of the teacher, but on the students' perceptions evoked by what occurs in the classroom, what students think about their teacher, and what they learn and do. Of course, intentions are important variables; they may influence the teacher's way 
of teaching, and thus they, for example, may help explain differences in the relationships of teachers with different classes, or with different students in one class.

Teachers' intentions can be important factors for designing training or for counseling about changes in patterns in interpersonal relationships between students and teachers (see the section on improving relationships). However, intentions have limited utility in helping to understand the pragmatic effects of communication. In the remainder of this chapter, we will focus on student perceptions, but will also include teacher perceptions when relevant.

\section{The model for interpersonal teacher behavior}

The perceptions of students about their interpersonal relationships with their teacher have been mapped and studied in our research with the Model for Interpersonal Teacher Behavior (MITB). This model is based on Timothy Leary's research on the interpersonal diagnosis of personality (1957) and its application to teaching (Wubbels, Créton \& Hooymayers, 1985). The Leary model has been investigated extensively in clinical psychology and psychotherapeutic settings (Strack, 1996) and has proven effective in describing human interaction (Foa, 1961; Lonner, 1980). While not conclusive, there is evidence that the Leary model is cross-culturally generalizable (Brown, 1965; Dunkin \& Biddle, 1974; Lonner, 1980; Segall, Dasen, Berry \& Poortinga, 1990). In the Leary model, two dimensions are important. Leary called them Dominance-Submission and Hostility-Affection. Although these two dimensions have occasionally been given other names, (i.e., Brown (1965) used Status and Solidarity, Dunkin and Biddle (1974) Warmth and Directivity), they have generally been accepted as universal descriptors of human interaction. The two dimensions have also been applied to education. Slater (1962) used these dimensions to describe pedagogical relationships, and Dunkin and Biddle (1974) demonstrated their importance in teachers' efforts to influence classroom events. Robertson (2002) used two similar dimensions, assertiveness and cooperation, to describe classroom management behavior.

Insert

Figures 1 and 2 about here

The sectors are labeled DC, CD, etc. according to their position in the co-ordinate system (much like the directions in a compass). For example, the two sectors 'leadership' and 'helpful/ 
friendliness' are both characterized by Dominance and Co-operation. In the DC-sector, the Dominance aspect prevails over the Co-operation aspect covering teacher enthusiasm, motivating, and the like. The adjacent $\mathrm{CD}$-sector includes more co-operative and less dominant perceptions; the teacher shows helpful, friendly, and considerate behavior. Figure 2 provides an overview of typical teacher behaviors that relate to each of the eight sectors of the Model.

\section{Measurement of perceptions of interpersonal teacher behavior}

For the measurement of students' perceptions of interpersonal teacher behavior, different instruments are needed, for the message and interaction level and for the pattern level.

\section{Message and interaction level}

At the message level, not much research on student perceptions has been carried out. Van Tartwijk (1993) and van Tartwijk, Brekelmans, Wubbels, Fisher and Fraser (1998) report-studies using an instrument to measure students' perceptions of interpersonal messages. These studies used two rating scales corresponding to the two dimensions of the Model (see Figure 3).

Observers were trained to take the role of students. These observers viewed lessons that had been videotaped from the back of the classroom and gave their estimation of the students' perceptions on the two rating scales for 180 fragments of 10 seconds (van Tartwijk, 1993) respectively and 68 fragments of one minute (van Tartwijk et al., 1998). The fragments were chosen randomly from 10 complete lessons, respectively 68 lessons and show various situations. In one a teacher is writing on the blackboard with his back to the classroom, and some students are listening, whereas others are talking. Another example shows the teacher speaking angrily to a student hitting another student with the class looking on. To establish reliability in both studies, several observers were used and acceptable inter-rater reliability (Kendalls' Tau between 0.69 and 0.81 and Pearson correlations between 0.71 and 0.82 were found). In a small-scale, study van Tartwijk (1993) also compared the observers' ratings with the ratings of three students resulting in Pearson correlations of over 0.80 . Further indications for validity were the 0.06 non-significant correlations between the ratings for the two dimensions.

Insert Figure 3 about here

Pattern level 
The perceptions of teachers and students at the pattern level can be measured with the Questionnaire on Teacher Interaction (QTI). To map interpersonal teacher behavior, the QTI was designed according to the two-dimensional Leary model and the eight sectors (Wubbels, 1985; 1987). It was originally developed in the Netherlands, and a 64-item American version was constructed in 1988 (Wubbels \& Levy, 1991). The Dutch items were formulated, based on large numbers of interviews with both teachers and students (Wubbels \& Levy, 1993). The original Dutch version consists of 77 items to be rated on a five-point Likert scale ranging from 'Never/Not at all' to 'Always/Very'. The items are divided into eight scales corresponding with the eight behavior types. The instrument has been translated into the following languages: English, French, German, Hebrew, Russian, Slovenian, Swedish, Norwegian, Finnish, Spanish, Mandarin Chinese, Singapore Chinese and Indonesian ${ }^{1}$. In Table 1 typical items are provided for each of the eight sectors of the QTI.

Table 1 Number of items and typical item for each of the eight scales of the Dutch and US version of the QTI.

\begin{tabular}{lllll}
\hline \multicolumn{4}{c}{ No. of items } & Typical item \\
& & Dutch & U.S. & \\
\hline DC & Leadership & 10 & 7 & S/He is a good leader \\
CD & Helpful/ Friendly & 10 & 8 & S/He is someone we can depend on \\
CS & Understanding & 10 & 8 & If we have something to say s/he will listen \\
SC & Student responsibility/ & 9 & 8 & S/he gives us a lot of free time in class \\
& Freedom & 9 & 7 & S/He seems uncertain \\
SO & Uncertain & 11 & 9 & S/He is suspicious \\
OS & Dissatisfied & 9 & 8 & S/He gets angry \\
OD & Admonishing & 9 & 9 & S/He is strict \\
DO & Strict & &
\end{tabular}

Students can rate their current teacher on the QTI, and teachers can also record their perceptions about their own behavior (their self-perceptions). Teachers may also record their

\footnotetext{
${ }^{1}$ The QTI was intended for use in Secondary Education and formed the basis of several new versions such as for Primary Education (e.g. Goh, \& Fraser, 1996) and for Higher Education teachers (e.g. Soerjaningsih, Fraser \& Aldridge, 2002), for supervisors of student teachers (Kremer-Hayon \& Wubbels, 1993a), and one for teachers about school managers (the Questionnaire on Principal Interaction, e.g. Kremer-Hayon \& Wubbels, 1993b; Fisher \& Cresswell, 1998). The instrument also formed the starting point for adaptations
} 
responses from the perspective of how they would like to be (i.e., their ideal perceptions). Each completed questionnaire yields a set of eight scale scores. Scale scores equal the sum of all item scores and are then rescaled to range between 0 and 1 . When the QTI has been administered to students, scale scores of students from the same class can be aggregated to a class mean.

In some studies reviewed for this chapter, the teacher-student relationship was analyzed on the basis of dimension scores (i.e., the scale scores are converted linearly to dimension scores $^{2}$ ). The closer scales are to the Dominance/Submission dimension (strict, leadership, uncertainty and student responsibility/freedom) the more they contribute to this dimension, and similarly helpful/friendliness, understanding, dissatisfied and admonishing contribute most to the Co-operation/Opposition dimension. Graphic representations of the eight scale scores ('interpersonal profiles') can be used to report on the teacher-student relationship (see Figure 11 for examples) $)^{3}$.

Several studies have been conducted on the reliability and validity of the QTI. These have included among others Dutch (e.g. Brekelmans, Wubbels \& Créton, 1990; den Brok, 2001; Wubbels et al. 1985), American (Wubbels \& Levy, 1991) and Australian (Fisher, Fraser \& Wubbels, 1992; Fisher, Henderson, \& Fraser, 1995). Recently, a cross-national validity study was completed comparing students' responses to the questionnaire in Singapore, Brunei, US, The Netherlands, Slovakia and Australia (den Brok, Fisher, Brekelmans, Rickards, Wubbels, Levy, \& Waldrip, 2003). In all these studies, both reliability and validity were satisfactory. The homogeneity of each of the eight groups of items expressed in internal consistencies (Cronbach's $\alpha$ ) for student ratings at class level is generally above .80 . The agreement between the scores of students in a single class usually meets the general requirements for observer agreement. The internal consistencies (Cronbach's $\alpha$ ), when students' scores in one class are considered as repeated measures are above .90 (Brekelmans, et al., 1990). Internal consistencies for teacher self-perceptions and teacher ideals are usually a bit lower, but hardly ever below 0.65 . The variance in students' ratings at the class level is much higher than for most other learning environments questionnaires indicating that the QTI discriminates well between classes. For the American version, the percentage of variance at the class level is between 36 and 59 (Wubbels, \&

\footnotetext{
that are being used in post-compulsory education (Hockley \& Harkin, 2000).

${ }^{2}$ To this end the eight scores are represented as vectors in a two dimensional space, each dividing a section of the model of interpersonal behavior in two and with a length corresponding to the height of the scale score. We then compute the two co-ordinates of the resultant of these eight vectors.

${ }^{3}$ These graphic representations are achieved by shading in each sector of the model of interpersonal teacher behavior. The ratio of the length of the perpendicular bisector of the shaded part and the length of the perpendicular bisector of the total sector equals the ratio of the observed score and the maximum score for that sector.
} 
Levy, 1991) and in the Dutch version, between 48 and 62 percent (e.g. den Brok, 2001). Although most of the variance in students' ratings is at the teacher level, there is an interaction between teacher level and the class level indicating that students perceive their teachers as varying in their relationships across classes (Brekelmans, den Brok, Bergen, \& Wubbels, 2004; den Brok, 2001; Levy, den Brok, Wubbels, \& Brekelmans, 2003). This effect is, however, not very large. From a generalizability, study (Shavelson, Webb \& Burstein, 1986) on students' ratings, it was concluded (Brekelmans 1989) that the QTI should be administered to at least ten students in a class for the data to be reliable. The QTI does not need to be administered more than once per year, since interpersonal style remains relatively stable. At least two classes of students should complete the questionnaire for each teacher for a reliable measure of overall style.

With respect to validity, for example, factor analyses on class means and LISREL analyses (den Brok, 2001; den Brok, Levy, Wubbels \& Rodriguez, 2003; Wubbels \& Levy, 1991) determined that the two-factor structure did indeed support the eight scales. For students' ratings Brekelmans et al. (1990) demonstrated that both factors explain 80 per cent of the variance on all the scales of the Dutch QTI. Similar results were obtained for the version in the other countries (den Brok, Fisher, et al., 2003). For both students' ratings and teacher self- and ideal perceptions, scales appear to be ordered in a circumplex structure, meaning that two, independent factors are found, with a circular ordering of the scales (Wiggins, Philips \& Trapnell, 1989).

\section{Interpersonal profiles}

To describe research results for interpersonal profiles, we first turn to the profiles of teacherstudent relationships that have been found with the help of the Model for Interpersonal Teacher Behavior and the QTI. A profile is the particular combination of eight scale scores resulting from the administration of the QTI. When describing patterns of interpersonal relationships in classrooms using cluster analyses of students' ratings, eight different types of profiles could be distinguished in Dutch and American classes (Brekelmans, 1989; Brekelmans, Levy \& Rodriguez, 1993) ${ }^{4}$.

These profiles have been named Directive, Authoritative, Tolerant/Authoritative, Tolerant, Uncertain/Tolerant, Uncertain/Aggressive, Drudging, and Repressive. In Figure 4, we summarize each of the eight types on the basis of the two dimension scores of the profile by means of a main point in the co-ordinate system. Although we characterize these profiles in terms of the teacher's style, it is important to remember that these are descriptions of a single teacher in one particular

\footnotetext{
${ }^{4}$ The fact that eight types of patterns have been found and that the QTI has eight scales may raise misunderstandings. The two eights have nothing to do with each other.
} 
class. Classes of experienced or veteran teachers usually have the same type of interpersonal pattern, but there can be differences between classes for the same teacher (Brekelmans, Wubbels, $\&$ den Brok, 2002). For beginning teachers, the variation across classes can be considerable (Brekelmans, et al., 2002; Somers, Brekelmans \& Wubbels, 1997).

Insert figure 4 about here

The Authoritative, the Tolerant/Authoritative and the Tolerant type are patterns wherein students perceive their teachers as relatively high on the Proximity Dimension, with the Tolerant type lowest on the Influence Dimension. Less co-operative than the three previous types are the Directive, the Uncertain/Tolerant and the Drudging type, with the Uncertain/Tolerant type lowest on the Dominance Dimension. The least co-operative patterns of interpersonal relationships have been indicated as Repressive and Uncertain/Aggressive. In Repressive type classes, teachers are the most dominant of all eight types.

In Table 2, descriptions of the classroom environment typical for each of the eight types are presented based on observation research (Créton \& Wubbels, 1984; Brekelmans 1989; Wubbels \& Levy, 1993).

Table 2. Descriptions of classroom environments typical for the eight typologies of interpersonal styles

\begin{tabular}{|c|c|}
\hline $\begin{array}{l}\text { Interpersonal } \\
\text { profile type }\end{array}$ & Classroom environment \\
\hline Directive & $\begin{array}{l}\text { The learning environment in a class with teachers with a Directive profile is } \\
\text { well structured and task-oriented. Directive teachers are organized efficiently } \\
\text { and normally complete all lessons on time. They dominate class discussion, } \\
\text { and generally hold students' interest. These teachers usually aren't really close } \\
\text { to their students, though they are occasionally friendly and understanding. } \\
\text { They have high standards and are seen as demanding. Things seem } \\
\text { businesslike, but the teachers have to work at it. They get angry at times and } \\
\text { have to remind the class that they are there to work. They like to call on } \\
\text { students who misbehave and are inattentive. This normally straightens them up } \\
\text { quickly. }\end{array}$ \\
\hline
\end{tabular}




\begin{tabular}{|c|c|}
\hline Authoritative & $\begin{array}{l}\text { The Authoritative atmosphere is well-structured, pleasant and task-oriented. } \\
\text { Rules and procedures are clear and students don't need to be reminded. They } \\
\text { are attentive, and generally produce better work than their peers in the } \\
\text { Directive teachers' class. Authoritative teachers are enthusiastic and open to } \\
\text { students' needs. They take a personal interest in them, and this comes through } \\
\text { in the lessons. Whereas their favorite method is the lecture, Authoritative } \\
\text { teachers frequently use other techniques. The lessons are well planned and } \\
\text { logically structured. }\end{array}$ \\
\hline $\begin{array}{l}\text { Tolerant and } \\
\text { Authoritative }\end{array}$ & $\begin{array}{l}\text { Tolerant and Authoritative teachers maintain a structure that supports student } \\
\text { responsibility and freedom. They use a variety of methods, to which students } \\
\text { respond well. They frequently organize their lessons around small group work. } \\
\text { While the class environment resembles the climate in the Authoritative class, } \\
\text { Tolerant/Authoritative teachers develop closer relationships with students. } \\
\text { They enjoy the class and are highly involved in most lessons. Both students } \\
\text { and teachers can be seen laughing, and there is very little need to enforce the } \\
\text { rules. These teachers ignore minor disruptions, choosing instead to concentrate } \\
\text { on the lesson. Students work to reach their own and the teachers' instructional } \\
\text { goals with little or no complaining. }\end{array}$ \\
\hline Tolerant & $\begin{array}{l}\text { There seem to be separate Dutch and American views of Tolerant teachers. To } \\
\text { the Dutch, the atmosphere is pleasant and supportive and students enjoy } \\
\text { attending class. They have more freedom in this class than in those above, and } \\
\text { have some real power to influence curriculum and instruction. Students } \\
\text { appreciate their teachers' personal involvement and their ability to match the } \\
\text { subject matter with their learning styles. They often work at their own pace and } \\
\text { the class atmosphere sometimes may be a little confused as a result. In the } \\
\text { U.S., however, Tolerant teachers are seen to be somewhat disorganized. Their } \\
\text { lessons are not prepared well and they don't challenge students. These teachers } \\
\text { often begin the lesson with an explanation and then send the students off to } \\
\text { individually complete an assignment. While the teachers are interested in } \\
\text { students' personal lives, their academic expectations for them aren't evident. }\end{array}$ \\
\hline $\begin{array}{l}\text { Uncertain/ } \\
\text { Tolerant }\end{array}$ & $\begin{array}{l}\text { Uncertain/Tolerant teachers are co-operative but don't show much leadership } \\
\text { in class. Their lessons are poorly structured, are not introduced completely and } \\
\text { don't have much follow-through. They generally tolerate disorder, and students }\end{array}$ \\
\hline
\end{tabular}




\begin{tabular}{|c|c|}
\hline & $\begin{array}{l}\text { are not task-oriented. Uncertain/Tolerant teacher are quite concerned about the } \\
\text { class, and are willing to explain things repeatedly to students who haven't been } \\
\text { listening. The atmosphere is so unstructured, however, that only the students in } \\
\text { front are attentive while the others play games, do homework, and the like. } \\
\text { Students are not provocative, however, and the teachers manage to ignore them } \\
\text { while loudly and quickly covering the subject. Uncertain/Tolerant teachers' } \\
\text { rules of behavior are arbitrary, and students don't know what to expect when } \\
\text { infractions occur. The teachers' few efforts to stop the misbehavior are } \\
\text { delivered without emphasis and have little effect on the class. Sometimes these } \\
\text { teachers react quickly, and at other times completely ignore inattentiveness. } \\
\text { Class performance expectations are minimal and mostly immediate rather than } \\
\text { long-range. The overall effect is of an unproductive equilibrium in which } \\
\text { teachers and students seem to go their own way. }\end{array}$ \\
\hline $\begin{array}{l}\text { Uncertain/ } \\
\text { Aggressive }\end{array}$ & $\begin{array}{l}\text { This class is characterized by an aggressive kind of disorder. Teachers and } \\
\text { students regard each other as opponents and spend almost all their time in } \\
\text { symmetrically escalating conflicts. Students seize nearly every opportunity to } \\
\text { be disruptive, and continually provoke the teachers by jumping up, laughing } \\
\text { and shouting out. This generally brings a panicked over-reaction from the } \\
\text { teachers, which is met by even greater student misbehavior. An observer in } \\
\text { this class might see the teacher and students fighting over a book that the } \\
\text { student has been reading. The teacher grabs the book in an effort to force the } \\
\text { student to pay attention. The student resists because he or she thinks the } \\
\text { teacher has no right to his or her property. Since neither one backs down, the } \\
\text { situation often escalates out of control. In the middle of the confusion } \\
\text { Uncertain/Aggressive teachers may suddenly try to discipline a few students, } \\
\text { but often manage to miss the real culprits. Because of the teachers' } \\
\text { unpredictable and unbalanced behavior, the students feel that the teacher is to } \\
\text { blame. Rules of behavior aren't communicated or explained properly. These } \\
\text { teachers spend most of their time trying to manage the class, yet seem } \\
\text { unwilling to experiment with different instructional techniques. They prefer to } \\
\text { think 'first, they'll have to behave'. Learning is the least important aspect of } \\
\text { the class, unfortunately. }\end{array}$ \\
\hline Repressive & Students of Repressive teachers are uninvolved and extremely docile. They \\
\hline
\end{tabular}




\begin{tabular}{|c|c|}
\hline & $\begin{array}{l}\text { follow the rules and are afraid of the teachers' angry outbursts. These teachers } \\
\text { seem to overreact to small transgressions, frequently making sarcastic remarks } \\
\text { or giving failing grades. Repressive teachers are the epitome of complementary } \\
\text { rigidity. These teachers' lessons are structured, but not well organized. } \\
\text { Whereas directions and background information are provided, few questions } \\
\text { are allowed or encouraged. Occasionally, students will work on individual } \\
\text { assignments, for which they receive precious little help from the teachers. The } \\
\text { atmosphere is guarded and unpleasant, and the students are apprehensive and } \\
\text { fearful. Since the Repressive teachers' expectations are competition-oriented } \\
\text { and inflated, students worry allot about their exams. The teachers seem to } \\
\text { repress student initiative, preferring to lecture while the students sit still. They } \\
\text { perceive the teachers as unhappy and inpatient and their silence seems like the } \\
\text { calm before the storm. }\end{array}$ \\
\hline Drudging & $\begin{array}{l}\text { The atmosphere in a Drudging teacher's class varies between the disorder with } \\
\text { the Uncertain/Aggressive and Uncertain/Tolerant teachers and sometimes the } \\
\text { Directive teacher's class atmosphere. One thing is constant, however: these } \\
\text { teachers continually struggle to manage the class. They usually succeed (unlike } \\
\text { the other two types), but not before expending a great deal of energy. Students } \\
\text { pay attention as long as the teachers actively try to motivate them. When they } \\
\text { do get involved, the atmosphere is oriented toward the subject matter and the } \\
\text { teachers do not generate much warmth. They generally follow a routine in } \\
\text { which they do most of the talking and avoid experimenting with new methods. } \\
\text { Drudging teachers always seem to be going downhill and the class is neither } \\
\text { enthusiastic nor supportive nor competitive. Unfortunately, because of the } \\
\text { continual concern with class management these teachers sometimes look as } \\
\text { though they are on the verge of burnout. }\end{array}$ \\
\hline
\end{tabular}

\section{Interpersonal relations across the teaching career}

From the outset of our research program, it appeared that many teachers were not sufficiently able to create positive learning environments. Beginning and experienced teachers encounter (different) problems in this domain. These problems can be described with the help of results of cross-sectional and longitudinal studies on the teacher student relationship and teacher experience level. In a first longitudinal study (e.g. Brekelmans, et al., 2002), data were gathered from 41 teachers (self- and ideal perceptions) and their students (actual perceptions) in the first 
three to eight years of their careers. The number of classes participating in gathering annual data varied from 1-5 per year per teacher.

A second longitudinal study (Somers, et al., 1997) used data of 197 student teachers (selfand ideal perceptions) and their students (actual perceptions) to follow them during teacher education and the first three years of their careers.

For a cross-sectional study (e.g. Brekelmans et al., 2002), data have been gathered from 573 teachers (self- and ideal perceptions) and more than 25,000 students (actual perceptions) located in about 100 different secondary schools throughout The Netherlands. Student teachers and teachers teaching all kind of subjects and from all parts of the Netherlands participated in the three studies. We first describe the development of the teacher-student relationship during the teaching career both at the level of dimension scores and at the level of the typology in Table 2 . Then we will turn to the character of the problems teachers encounter.

\section{Proximity and Influence dimensions}

In both longitudinal studies, teachers' ideal perceptions appeared to be stable during the first decade of their careers for both dimensions. Whereas teachers' self-perceptions and students' perceptions on the Proximity dimension hardly changed. It appeared that dominant behavior grew for most teachers toward their ideal every year in the first eight years of their careers. The variation among individual teachers, however, can be large. As an example, Figure 5 shows for both students' perceptions and teachers' self- and ideal perceptions, the growth rates for an 'average' teacher along with two lines representing the growth rate for teachers one standard deviation above and below average. For some there is a significant upward trend and for others downward, resulting in an average of no growth.

Insert Figures 5, 6 and 7 about here.

Figures 6 and 7 plot the mean Influence (DS) and Proximity (CO) scores for students' and teachers' ideal and self-perceptions based on cross-sectional data. The mean Influence and Proximity scores of teachers' ideal perceptions did not differ significantly ( $5 \%$ level) across levels of seniority (grouped in 6 stages, see Figure 6). Throughout their careers, teachers apparently agree on the amount of influence and proximity desired in the classroom. Students' and teachers' perceptions of actual behavior, however, varied noticeably for teachers across 
experience levels. Students' perceptions of the dominant behavior of student teachers and teachers with 1-5 years' experience also differed significantly from the other five groups. An increase in dominant behavior could be seen from the student teaching period through 6-10 years. After this point, there was little change. Teachers' self-perceptions showed the same pattern. The upward trend in students' and teachers' self-perceptions found in the longitudinal study possibly levels off after the first decade of teaching.

In the cross-sectional study, the experience-related differences in the Proximity dimension were much smaller than on the Influence dimension and only a few were significant. According to students, student teachers behaved more co-operatively than 1-5 and 11-15 year teachers. For teachers' self-perceptions, only the difference between student teachers and teachers with 11-15 years of experience were significant. This indicates a moderate decline in Proximity scores throughout the career. Apparently, when teachers grow older they appear to distance themselves from their students making the classroom atmosphere less personal and more businesslike

An interesting detail in the results of the second longitudinal study was a dip in the students' perceptions of dominance in the second student teaching placement. This means that the students perceive less leadership and more uncertainty. Student teachers participated in two placements, in the first in a group of three students with continuous observation of a co-operating teacher and in the second individually without observations. The dip can be interpreted from the reality shock perspective (e.g. Corcoran 1981; Muller Fohrbrodt 1978). In the first student teaching practicum (the triad period), the environment is relatively safe and the 'mistakes' of the student teachers in management and leadership behavior do not have full (negative) consequences for the classroom atmosphere. The presence of the co-operating teacher may keep the students in order and protects the student teacher so that a positive classroom atmosphere does not deteriorate. In the student teacher's individual placement, however, without the shield of the co-operating teacher, student teachers bear the full consequences of their behavior. This results in more discipline problems, and student teachers do experience the need to show more leadership and less uncertain behavior. It is, however much more difficult now to enforce the positive working environment than with the help of the co-operating teacher. Students perceive student teachers now lower on leadership and higher on uncertainty than before, and according to the students, apparently their student teachers are not able to be convincing leaders. It appears that they have not yet found how to do this. The higher levels in the first year show that they learn in this domain during the second placement.

\section{Profiles}

As an example of profile results, Table 3 presents the percentages of mean interpersonal 
profiles (students' perceptions) for the first and second student teaching placement and the first and second year of the professional career (Somers, et al., 1997).

Table 3. Percentages of mean interpersonal profiles (students' perceptions) for the first and second student teaching placement (STP) and the first and second year of the career

\begin{tabular}{l|lllll}
\hline \multicolumn{1}{c|}{ Interpersonal profile type } & $\begin{array}{c}\text { First STP } \\
(\mathrm{n}=197)\end{array}$ & $\begin{array}{c}\text { Second STP } \\
(\mathrm{n}=197)\end{array}$ & $\begin{array}{c}\text { First year } \\
(\mathrm{n}=55)\end{array}$ & $\begin{array}{c}\text { Second year } \\
(\mathrm{n}=19)\end{array}$ \\
\hline Directive & 2 & 4 & 11 & 5 & \\
Authoritative & 10 & 7 & 15 & 42 \\
Tolerant and authoritative & 11 & 11 & 11 & 11 \\
Tolerant & 50 & 47 & 42 & 32 \\
Uncertain/tolerant & 25 & 28 & 16 & 11 \\
Uncertain/aggressive & 2 & 1 & - & - \\
Repressive & - & - & - & - \\
Drudging & 1 & 3 & 5 & - \\
\hline
\end{tabular}

Table 3 shows that the major profiles in the student teaching placement were the Tolerant and the Uncertain/Tolerant profile. A larger proportion of interpersonal profiles fitted the more structured and task-oriented Authoritative profiles in the first and second year of the career.

Brekelmans, et al. (2002) found that of all ideal perceptions, three-fourths (73\%) were most similar to the Tolerant and Authoritative profile, while $25 \%$ were most similar to the Authoritative type. At all experience levels, more than $90 \%$ of the teachers preferred one of these two relatively similar interpersonal profiles.

As to the interpersonal profiles, it appears that according to their students, the most frequently found profiles in the first year of the teaching career are the Tolerant and the Uncertain/Tolerant profile. More student teachers than first-year teachers conform to the Tolerant and Uncertain/Tolerant type. The presence of these profiles decreases, as teachers get more experienced. Then, according to their students, a larger proportion of interpersonal profiles of teachers fit the more structured and task-oriented Authoritative and Directive profiles. During the first decade of the teaching career, the number of Authoritative profiles increases, and after about five years of experience the Directive type moves to the top. Toward the end of the teaching career, the number of teachers with a Repressive profile increases (Brekelmans, et al. 2002).

\section{Relational problems of teachers}

For many beginning teachers, it appears to be difficult to create and maintain order in class (e.g. Veenman 1984), and this can be seen from the relatively low students' perception score 
on leadership and high scores on uncertainty at the beginning of the career discussed in the previous section. It appears that most teachers learn to cope with these problems in the first years of their careers. The growth of the frequency of the Repressive teacher type toward the end of the career suggests that older teachers have a specific problem in their relationships with students: they become overly strict and authoritarian.

\section{Beginning teachers}

One explanation for the observations described in the previous section may be the following. At the start of their careers, most teachers are twenty to twenty-five years old and have not, to any large degree, served in leadership roles. From this point of view, the professional role does not coincide very well with their stage of personal development. Beginning teachers are often confronted with the lack of a behavioral repertoire (in particular in managerial and instructional strategies) and inadequate cognitions in this area. This can result in students' perceptions of their interpersonal style as Uncertain/Tolerant and Tolerant, with a relatively low influence score. This situation urges teachers to do something about it. The need for change is reinforced by the ideal perception of beginning teachers, mainly a classroom situation with the teachers (themselves) in control. Through daily classroom practice, the young teachers may learn how to develop dominance patterns. This interpretation is consistent with Huberman's (1993) description of modal sequences in the professional engagement of teachers during their careers (survival and discovery, stabilization, experimentation/diversification). The first two phases of Huberman's sequence (survival and discovery) can be recognized from the preceding discussion.

According to the preceding interpretation, beginning teachers mainly attribute (consciously or unconsciously) problems in interacting with students to the influence area. The ability to empathize with students (recent peers) and to show co-operative behaviors is considered by them to be a less problematic area. The greater attention to Dominant behavior is probably reflected in the fact that there is more dispersion with teachers' perceptions of the Influence dimension than with students' perceptions, whereas students perceive larger differences between teachers on the Proximity dimension (e.g. Levy, et al., 2003; den Brok, Levy, Rodriguez \& Wubbels, 2002). With the greater attention to Dominant behavior, practice and experimentation on the Proximity dimension fade somewhat into the background. The above interpretation of the differences in changes in Dominant and Co-operative behavior is relevant when teachers show an increase in Dominant behavior (as most teachers do) and rather stable or decreasing Co-operative behavior. There are teachers with an increase in Co-operative behavior in the first-years of their teaching careers. This may be due to an increasing behavioral repertoire and/or a better 
understanding of classroom processes.

\section{Experienced teachers}

Considering the descriptions of the repressive teacher in Table 2, the growth of the number of repressive teachers, also visible in decreasing Co-operative behavior towards the end of the teaching career, is problematic. We suppose that the decrease of co-operative behavior is not due to a lack of an adequate behavioral repertoire in the co-operative sectors. We think that especially some very experienced teachers tend to become stricter when they get older, becoming sometimes unreasonable in their demands. Because of the distance, both emotionally and in age, older teachers may be less connected with the students' life styles. Therefore, these teachers may become more and more dissatisfied with student behavior, thus becoming a problem for themselves as well as for their students. These high demands on, and low connection with, students can provoke student protest that at first can be handled easily, but can gradually become a real threat for a positive classroom atmosphere. Thus the teachers are faced with a difficult problem, and they may feel required to act in an even more demanding and admonishing manner, stimulating a negative communicative spiral: the teacher showing ever more oppositional behavior as a reaction to students' protest behavior. So the origin of the decrease in co-operative behavior may be due to an inadequate repertoire, and inadequate cognitions about the cause of the problem. Giving responsibility to students is inherently risky, because it appears that many people when they intend to give responsibility also show uncertainty ${ }^{5}$. This uncertainty can provoke student disorderly behavior and shape undesirable classroom situations. Teachers need to be able to give students responsibility for their own work without showing uncertainty or demonstrating weakness. Training to give students freedom and responsibility thus may be a prominent part of in-service education for very experienced teachers. In addition, training on setting norms and standards in a clear, but not provocative way may also be useful.

\section{Teacher position in class and non-verbal behavior}

This section first reports on studies on the position of the teacher in class and then about non-verbal behavior. According to the systems approach, non-verbal behavior is particularly important for the perception of the relationship aspect of communication. Differences between beginning and experienced teachers in non-verbal behavior in relation to the position in class may help explain problems of beginning teachers.

\footnotetext{
${ }^{5}$ The closeness of these two sectors in the model (implying high correlations between the two adjacent scales) is an empirical validated indication of this.
} 


\section{Position}

In a joint Dutch and Australian study, the relationship between the students' perceptions of their teacher's interpersonal style and judges' ratings of the interpersonal aspect of these teachers' messages was investigated (van Tartwijk, et al., 1998). Strong and strong to medium significant correlations were established between students' perceptions and judges' ratings during whole-class teaching whereas no significant correlations were found between students' perceptions and judges' ratings during individual seatwork. These findings suggest that teachers who present themselves as teachers with a specific interpersonal style when they have a central position in the classroom (when they are "on stage"), will probably create a working climate that will last for the whole lesson and beyond. Whole-class teaching seems important for establishing the 'image' the students have of their teacher. Subsequently, this image will also guide the students' communication with their teacher during seatwork (cf. Weber and Mitchell, 1995).

\section{Non-verbal behavior}

Van Tartwijk (1993) studied the contribution of non-verbal behaviors to the perception of the relationship at the message level with the help of five channels of behavior (cf., Harper, Wiens \& Matarazzo, 1978): space (the teacher's use of classroom space ); body (position and movement of the trunk, arms and head), face (various expressions), visual behavior (duration of the teacher looking at the students), and voice (the non-content aspects of speech). About one thousand 8-second video fragments selected from the videotaped lessons of 53 teachers at work in their classrooms were shown to raters. The raters estimated the students' perception of the teacher behavior in these fragments on rating scales corresponding to the Influence and Proximity dimensions (Figure 3). Subsequently the nonverbal behavior in the fragments was scored with a specially designed observation instrument for nonverbal teacher behavior.

Insert Figures 8, 9 and 10 about here.

All channels could be used to explain variance in the Influence ratings, with voice being by far the most important. Figure 8 presents this relationship for voice. In this figure, nonverbal behaviors were plotted on a vertical axis according to the mean DS rating. The mean CO ratings of nonverbal behaviors were plotted on the horizontal axis. Only the Face and Voice channels 
were important for explaining variance in the $\mathrm{CO}$ ratings, with the facial expression having the strongest relationship (see Figure 9).

A summarizing view across channels is presented in Figure $10^{6}$. The figure to the left shows that behaviors such as looking at the students continuously and speaking loud and emphatically were often observed together. On average, this combination of behaviors was rated as highly dominant. In the Figure to the right, we see that the behaviors such as not being heard, being close to the students, and bending toward the students often go together and yield a low influence score.

\section{Beginning teachers' problems}

In Kounin's (1970) landmark study on discipline problems and classroom management, it was found that management success of teachers, in terms of freedom from deviancy, correlated with "with-it-ness" (the teacher demonstrates that he or she knows what is going on) and "overlapping" (the teacher's ability to attend to two issues simultaneously). The major relationship in the study by Van Tartwijk (1993) between nonverbal behaviors and interpersonal perception can be interpreted using Kounin's concepts: the more the teacher facilitates visual contact with the class, the more his or her behavior is perceived as dominant. When nonverbal behaviors such as visual contact with class and emphatic verbal presence (speaking continuously with a loud voice) are combined, the teacher's messages were rated most dominant.

However, there appeared a distinct difference between beginning and experienced teachers' nonverbal behavior that may be an important cause for the unsatisfying relationships of some beginning teachers with their students. Behaviors that facilitated visual contact (looking to students) and signaling with-it-ness and overlapping were demonstrated by experienced teachers almost twice as much as by student teachers. These behaviors are typical for teachers during whole-class teaching. No differences were found between beginning and more experienced teachers for the nonverbal behaviors that are typical for a teacher interacting with individual students, such as speaking in a low volume, head and trunk bent forward, and a non-frontal body orientation toward the majority of students in the class (see the right of Figure 10). This indicates that the nonverbal behaviors of beginning and experienced teachers differ, not so much when they interact with individual students during individual seatwork, but foremost during whole-class

\footnotetext{
${ }^{6}$ This figure is based on the results of a Homals analysis, a technique for optimal scaling. In this analysis fragments are quantified in such a way that fragments that resemble each other get a similar value on a dimension, whereas fragments which do not resemble get a more different value. This analysis was used to identify the combinations of nonverbal behaviors from the various channels that occurred relatively often together.
} 
teaching.

The results above support the need for beginning teachers to portray the image of an experienced teacher whenever they address the class as a group. However, they probably should avoid whole class teaching for a longer period. Staying on-stage too long often increases the risk of not being able to sustain one's part.

\section{Teacher interpersonal behavior and cognitive and affective outcomes}

Classroom environment studies that have included the interpersonal perspective on teaching usually indicate a strong and positive relationship between perceptions of Influence and Proximity or their related subscales and cognitive and affective student outcomes.

Profiles

The Brekelmans (1989) study investigated the relationship between student outcomes and students' perceptions of teacher interpersonal behavior in terms of the interpersonal profiles as described in Table 2. In Table 4, estimations for the (statistical) effects of the eight different profiles of students' perceptions of interpersonal profile type on physics achievement and attitude scores are presented (after correction for the influences of other variables).

Table 4. Effects on achievement and attitudes of students' perceptions of the interpersonal profile of their physics teachers ${ }^{7}$

\begin{tabular}{lll}
\hline Interpersonal profile type & Effect on achievement & Effect on attitude \\
\hline 1 Directive & 0.17 & 0.62 \\
2 Authoritative & 0.07 & 0.79 \\
3 Authoritative/Tolerant & Missing ${ }^{\text {a) }}$ & Missing \\
4 Tolerant & 0.23 & 0.53 \\
5 Uncertain/Tolerant & -0.17 & 0.51 \\
6 Uncertain/Aggressive & -0.15 & 0.20 \\
7 Repressive & 0.40 & 0.38 \\
8 Drudging b) & 0 & 0 \\
${ }^{\text {a) }}$ Too few cases to include in the analyses; ${ }^{\text {b) }}$ reference group
\end{tabular}

a) Too few cases to include in the analyses; ${ }^{\text {b) }}$ reference group

The results of Table 4 show that, on average, the teacher with a Repressive profile has the highest achievement outcomes. Teachers with disorderly classrooms (Profiles 5, 6, 8) reflect relatively low student achievement, whereas Directive, Authoritative and Tolerant teachers have

\footnotetext{
${ }^{7}$ The signs have no absolute meaning. In the analysis one of the types has to be chosen as point of reference. This is the Drudging type and the numbers and signs indicate the position relative to this type.
} 
relatively high outcomes. The Authoritative and Directive teachers have the highest student attitude scores. Students of the Drudging, Uncertain/Aggressive and Repressive teachers have the worst attitudes toward physics.

\section{Scales, dimensions and cognitive outcomes}

In Brekelmans' (1989) study, students' perceptions of teacher Influence were related to cognitive outcomes. The higher a teacher was perceived on the Influence dimension, the higher the outcomes of students on a Physics test. In her study, teacher influence was the most important variable at the class level. Other studies found positive correlations or regression coefficients for the leadership scale and cognitive student outcomes (Goh \& Fraser, 2000; Henderson, 1995).

Similar relationships have also been found for the Proximity dimension and Proximity related scales such as helpful/friendly and understanding, and to a lesser degree student responsibility/freedom (Goh \& Fraser, 2000; Henderson, 1995; Evans, 1998). The more teachers were perceived as co-operative, the higher students' scores on cognitive tests. However, relationships between proximity and cognitive outcomes are not always straightforward. In some studies, it could only be proven that opposition, or dissatisfaction and admonishing behavior were related to lower performance, but not that friendliness and understanding behavior related were to higher performance (Rawnsley, 1997). In other studies, the relationship between proximity and cognitive outcomes is not linear, but curvilinear (i.e., lower perceptions of proximity go with low outcomes, but intermediate and higher values with higher performance until a certain ceiling of optimal proximity has been reached; den Brok, 2001; den Brok, et al., in press). If report card grades have been used as outcome measures, relationships with interpersonal behavior are inconclusive (Levy, Wubbels, \& Brekelmans, 1992; Van Amelsvoort, Bergen, Lamberigts, \& Setz, 1993; Van Amelsvoort,1999). No relationship between student perceptions of teacher proximity and influence and their report card grades was found in these studies. In Figure 11, a graphical profile is displayed of two Physics teachers (from the Brekelmans study), one with relatively high and one with relatively low student achievement.

\section{Insert Figures 11 and 12 about here.}

\section{Scales, dimensions and affective outcomes}

Studies investigating associations between the teacher-student relationship and affective outcomes display a much more consistent pattern than studies investigating the relationship with 
cognitive outcomes. All studies find a positive relationship of both influence and proximity with affective outcome measures, usually measured in terms of subject-specific motivation. Generally, effects of proximity are somewhat stronger than effects of influence. In a study with Physics teachers and their students, Brekelmans (1989) found a clear relationship between proximity and student motivation for Physics. In Figure 12 graphical profiles are presented from two Physics teachers, one with relatively low and one with relatively high student attitudes.

The higher the perception of proximity is, the higher the motivation of the students. With more specific measures of students' subject-specific motivation, other studies found positive relationships for helpful/friendly and understanding behavior with pleasure, confidence, effort and relevance of students (Derksen, 1994; van Amelsvoort et al., 1993; Setz, Bergen, van Amelsvoort, \& Lamberigts, 1993; van Amelsvoort, 1999). Strong and positive associations have also been demonstrated between several interpersonal scales, such as leadership and helpful/friendly, and affective outcomes, while negative relationships have been found with admonishing, dissatisfaction, and, in most cases, strictness (Goh \& Fraser, 2000; Henderson, 1995; Rawnsley, 1997; Evans, 1998; van Amelsvoort, et al., 1993; Setz, et al., 1993; van Amelsvoort, 1999). The weakest associations have been found between interpersonal behavior and confidence (Derksen, 1994; van Amelsvoort et. al., 1993; Setz, et al., 1993; van Amelsvoort, 1999). Van Amelsvoort (1999) demonstrated that the effect of interpersonal teacher behavior on students' subject-specific motivation is both direct as well as indirect via student motivation and regulation processes. In his study, a causal model was tested that linked students' perceptions on the QTI (in terms of dimension scores) to students' pleasure, confidence and effort. He found two (statistically) significant causal paths leading from proximity to students' pleasure: one path linked the two variables directly, the other path linked proximity to student regulation of emotions, which in turn affected effort, and effort affecting pleasure. Teacher proximity as perceived by students may thus both directly affect students' state-of-mind, but also indirectly via learning activities performed by students.

In a recent study on English as Foreign Language (EFL) teachers, den Brok (2001) found that interpersonal behavior was mainly related to the affective student outcomes, whereas other kinds of behavior were more relevant for cognitive outcomes. For all of the affective student outcome variables - pleasure, relevance, confidence and effort - a positive and strong effect was found for teacher proximity. For some of the affective variables - pleasure, relevance and effort influence also had a positive effect.

\section{Students' learning activities}


Some of the most important mediating factors between students' perceptions of teacher behavior and student outcomes are student's learning activities (Shuell, 1996; den Brok, Bergen \& Stahl, 2002). These learning activities are, in turn, very likely to originate from students' perceptions of their teachers' regulation of learning activities and interpersonal behavior (den Brok, et al., 2001). Brekelmans, Sleegers and Fraser (2001) investigated relations between students' perceptions of interpersonal teacher behavior and students' perceptions of teacher elicitation and regulation of learning activities, in particular the degree to which teachers activated students to perform and initiate in learning activities by themselves (teaching for active learning). Somewhat surprisingly, increasing perceptions of teacher activation seemed to be helped by stronger perceptions of influence. A similar result was found in another study on EFL teachers (den Brok, 2001). This perhaps can be understood from the earlier reported result that teaching at central moments in the lesson is crucial for the kind of relationship that develops (van Tartwijk et al., 1998). From this study it appeared that in these moments leadership will be shown quite naturally, whereas the responsibility given to students comes more to the fore during group and independent work, lesson segments that contribute less to the general perceived teacherstudent relationship. To give students appropriate freedom and responsibility during group and independent work, it appeared to be important for a teacher to be a strong leader in central lesson segments. The learning environment they create in central moments lives further in individual work.

\section{Conclusion}

In general, we conclude from the studies mentioned above that with respect to student outcomes appropriate teacher-student relationships are characterized by a rather high degree of teacher influence and proximity towards students. Interestingly and reassuring, results of studies on students' and teachers' preferred teacher-student relationships (e.g. Créton \& Wubbels, 1984) support the appropriateness of high amounts of influence and proximity.

\section{Relations between teachers' and students' perceptions}

Studies have shown usually considerable differences between teachers' and students' perceptions of learning environments (e.g. Fraser, 1998). We first discus the correlations between scales of the various perceptions, then we turn to the scores and differences between scores, and finally, we focus on a comparison of the teacher, student, and ideal profiles.

\section{Scale correlations}


Wubbels et al. (1987) calculated correlations between the students' perceptions scale scores and teachers' self-perception scale scores. They showed that the correlations between the scales of the teachers' self-perceptions and the students' perceptions were highest for scales of the same sector in the model. So for example the teachers' self-perception on DC correlates highest with the students' perception on DC and lower with other students' perception scales. The correlations, however, even between the same scales in the model were only moderately high, ranging between 0.18 and 0.53 , implying some disagreement between teachers and students. Students and their teachers agreed most about the amount of the teacher's leading and strict behavior and least about their understanding and friendly behavior.

\section{Scale and dimension scores}

Although a small number of studies reported non-significant differences between students' and teachers' perceptions (Ben-Chaim \& Zoller, 2001; Wubbels \& Levy, 1991) most studies show rather distinct differences on the level of scale scores as well as on the level of the dimensions of influence and proximity (Brekelmans \& Wubbels, 1991; Brekelmans, Levy, et al., 2002; Fisher, Fraser, Wubbels \& Brekelmans, 1993; Levy, Wubbels \& Brekelmans, 1992; Wubbels \& Brekelmans, 1997). On average, teachers reported higher ratings of their own leadership, helpful/friendly and understanding behavior than did their students, whereas they reported lower perceptions of their own uncertain, dissatisfied and admonishing behavior (e.g. den Brok, Levy, et al., 2002; Fisher \& Rickards, 1999; Harkin \& Turner, 1997; Rickards \& Fisher, 2000; Wubbels, Brekelmans \& Hermans, 1987; Wubbels, Brekelmans \& Hooymayers, 1992; Yuen, 1999). Some studies also reported higher teacher than student perceptions of strictness and lower teacher than student perceptions of giving responsibility (Fisher \& Rickards, 2000; Rickards \& Fisher, 2000).

Behaviors for which teachers reported higher perceptions than their students - leadership,

helpful/friendly and understanding - have found to be positively related to student achievement and motivation, whereas behaviors for which lower teacher than student perceptions were reported were negatively associated with student achievement and motivation. This means that many teachers made a more favorable judgment about the learning environment than did their students.

\section{Ideal, self and student profiles compared}

In a study by Wubbels et al. (1992) for the differences between teacher self-, ideal, and students' perceptions, the mean of the eight differences on the scales of the QTI was taken as a 
general difference measure for a profile. This mean difference between self- and students' perception as well as between ideal and self-perception was for 92 percent of the teachers far larger than the measurement errors. The differences are most distinct for the ideal and students' perceptions of the behavior. So according to the students' views, most teachers do not attain their ideal. From the difference between self-report and ideal, we see that also teachers think that they do not reach their ideal.

It appears that the more the teacher and his or her students disagree in their perceptions of teacher behavior, the more students perceive the teacher as uncertain, dissatisfied and admonishing. These types of behavior have been shown to be counterproductive with respect to the promotion of cognitive and affective student outcomes. Studies indicate that if student perceptions of influence and proximity were higher, the difference between students' and teachers' perceptions was smaller (Brekelmans \& Wubbels, 1991; Wubbels, et al., 1987; 1992). In the study by Wubbels et al. (1992) it was shown that for about two third of the teachers the teacher's perception of his or her own behavior occupies a position between the teacher's ideal about interpersonal behavior and the students' perception. An example is shown in Figure 13. These teachers see their behavior more like their ideal than their students. Thus, the difference between students' and the teacher's perceptions could be caused by wishful thinking on the part of the teacher, that may have the function to reduce cognitive dissonance (Festinger, 1957).

Insert Figures 13 and 14 about here.

For another group of teachers (about one third), the self-report is lower than the students' perceptions of the actual behavior, whereas the ideal is higher than both actual behavior and selfreport. An example of this pattern is found in Figure 14. The teachers in this group view their behavior more negatively (in the light of their ideal) than it is. This arrangement of profiles can function to protect the teacher against potential disappointment resulting from confrontation with more negative students' perception. Evidence for the influence of such thought processes was found in teachers' explanations of their own ratings (Wubbels, Brekelmans \& Hooymayers, 1993).

It remains unclear to what extent differences in perceptions may be related to teacher experience. A cross-sectional study by Brekelmans and Wubbels (1991) showed no significant relationships between teacher experience and the difference between students' and teachers' 
perceptions of influence and proximity. However, longitudinal studies indicate that differences with respect to proximity become larger during the teaching career, whereas they remain equal or become smaller for influence (Brekelmans, et al., 2002; Brekelmans, Holvast \& van Tartwijk, 1993). Other evidence is provided by a small study involving 6 individual teachers and qualitative data in the form of classroom observations and teacher interviews (Fisher, Fraser \& Creswell, 1995). In the latter study, however, experience seemed to influence differences in perceptions together with (initial) interpersonal teaching style.

Differences between students' and teachers' perceptions of interpersonal behavior may also be related to ethnicity or cultural background of teachers and students. In one study, differences between Caucasian-American students and their Caucasian teachers were lower than between Asian-American or Hispanic-American students and their (Caucasian) teachers (Levy, Wubbels, Brekelmans, \& Morganfield, 1997). A study comparing U.S. and Dutch teachers showed that statistically non-significant differences between American students and their teachers were somewhat smaller than between Dutch students and their teachers (Wubbels \& Levy, 1991). In a third study, Hispanic-American teachers displayed larger divergence with all of their students (whether being Hispanic-American, Asian-American, Caucasian-American, African-American or Native-American) than did Asian-American teachers (den Brok, Levy, et al., 2002). However, the latter study also showed that divergence between teacher and student perceptions is not related to both participants 'being of the same cultural background.'

\section{Improving relationships}

From the research studies reviewed we have clear indications what interpersonal relationships with students teachers should strive for and what non-verbal behaviors when having a central position in class are helpful in creating these positive relationships. It is desirable that teachers develop dominant and co-operative behavioral patterns and accompanying cognitions and attitudes. Further the importance of accurate teacher perceptions of their relationship with students has been established. This section will suggest intervention and QTI feedback strategies, and mention results of an intervention study.

\section{Intervention strategies and feedback}

Training for beginning teachers in strict and leadership behavioral skills may be effective in developing both the Influence and the Proximity dimension. Adequate differentiation between 'leadership' and 'strict' behavior and between 'freedom and responsibility' and 'uncertain' behavior (the transition from the co-operative to the opposite sectors of the Model of 
Interpersonal Behavior) is vital, but complex. It is our experience that a behavioral training component to improve relationships on the Influence dimension is crucial, because especially beginning teachers often lack an adequate behavioral repertoire. We think the Proximity dimension may require procedures and interventions in teacher education that are somewhat different from the behavioral emphasis on the Influence dimension. On the Proximity dimension, a cognitive component to training and staff development may be more important, in order to help teachers to use their skills more adequately and to help them select the appropriate skills in particular situations. Giving teachers insight into the circular processes of communication and the futility of trying to solve the problem by blaming the other party may help to activate interpersonal behavior that was already part of their behavioral repertoire.

The QTI can be used as a feedback instrument for teachers. It can be useful to compare student and teacher self and ideal perceptions e.g. in the light of the two possible different positions of these three perceptions to each other. Further, it is important for teachers when they interpret their profiles to be aware of the stage they are in in their careers because of the changes that have been found in relationships during the teaching career. For a teacher administering the questionnaire several years in a row, may help to monitor and influence the development of relationships during the career. For professional development purposes, comparison of the students and teacher perceptions in different classes may be helpful: teachers might learn from the perception in what they consider as good classes for classes where relationships with student are not that well. For this purpose, we have good experiences with interviews of the teacher with their students based on the data gathered with the questionnaire. In these interviews one can try to find out what is going on in the minds of the students. The most important function of these interviews is however to engage in meta-communication. According to Watzlawick et. al (1967) this kind of communication by itself helps to improve relationships.

Although we have some informal evidence the number of intervention studies that can corroborate the ideas presented above about the use of the QTI as a feedback instrument unfortunately is scarce. In a program in Brunei, aiming at stimulating teachers' science teaching (by reducing their teacher-centered role and their inclination to stimulate rote learning) teachers' behavior was assessed with the QTI (Scott, Fisher \& den Brok, 2003). Analyses of variance showed that project teachers were perceived as more helpful/friendly than as non-project teachers at the same schools. However, this study used only a post-treatment measurement (no pre-test). As part of a Dutch professional development program focusing on teaching for active learning, teachers were also coached with respect to their interpersonal competencies (Derksen, 1995). This 18-week program consisted of coaching on the job, university and school-based meetings and 
assessment by means of questionnaires, one of these being the QTI. Because interpersonal teaching competencies were regarded as important prerequisites to teaching competencies for active learning, the first three to five weeks of the program teachers were mainly coached with respect to the teacher-student interpersonal relationship. (For a few teachers, interpersonal teacher behavior covered the whole program.). Analyses of variance on data of 15 teachers from one school (out of five) participating in the program showed some changes in interpersonal teacher behavior (Derksen, 1995). The QTI was administered three times: before and directly after the professional development program, as well as four months after the program (retention measurement). Directly after the training, teachers, on average, were perceived as more uncertain by their students. After four months, however, teachers were perceived as more friendly, as providing more student responsibility/freedom and as less dissatisfied, admonishing and strict. Moreover, uncertainty had decreased again and was on the level as just before the program.

\section{Concluding remarks}

It can be concluded that the systems approach to classroom communication and the Model for Interpersonal Teacher Behavior have contributed significantly to our understanding of classroom management processes. The importance of high influence and proximity perceptions at the pattern level has been related to nonverbal aspects at the message level when teachers are in a central position in class. Studies on the teaching career send clear messages to pre-service and inservice teacher education.

The studies reviewed in this chapter showed that the QTI is a useful research tool, but research on the QTI as a feedback instrument for teachers is insufficient to prove its usefulness. The QTI meets the standards of the American Evaluation Association (1999) for accuracy, reliability and validity. The use of the QTI is practical in the light of time and money involved in administering the questionnaire and calculating the results and the intrusiveness of the process. Throughout this chapter we have considered student and teacher perception data as a value in its own: the teacher and his or her students have perceptions of their relationship and both are significant for research and for professional development. At the end of this chapter, it might be useful to mention that in secondary education students' perceptions usually have a high quality (e.g. d'Apollonia \& Abrami, 1996): they bare stronger resemblance to observer data than teacher's self-perceptions do (Marsh, 1982). Nevertheless we want to emphasize that for feedback or evaluation purposes the QTI needs to be used in a respectful way and embedded in appropriate, open and fair procedures and taking the differences in teachers careers, and differences across classes into account. The students' perceptions are only one of the possible inputs and certainly 
not the last or only word.

The research program is to be continued both in the Netherlands and in other parts of the world. Recent and ongoing studies on interpersonal relationships include the teacher-student relationships in multicultural classrooms and the classroom management competence of teachers in these settings. Much needed and on its way are intervention evaluations e.g., in teacher training programs for interpersonal teacher behavior. For input in such programs, a recently started study on the development of relationships in the first 10 lessons in a class will be significant. 


\section{References}

Amelsvoort, J. van (1999). Perspective on instruction, motivation and self-regulation. [In Dutch] Unpublished Doctoral Dissertation. Nijmegen: Katholieke Universiteit Nijmegen.

Amelsvoort, J. van, Bergen, Th., Lamberigts, R., \& Setz, W. (1993). Teacher behaviour, student motivation and school outcomes. [In Dutch] Nijmegen: Katholieke Universiteit Nijmegen/ITS.

American Evaluation Association (1999). The personnel evaluation standards. Summary of the standards. Retrieved from www.eval.org/EvaluationDocuments/perseval.html

d'Apollonia, S., \& Abrami, P. (1996). Variables moderating the validity of student ratings of instruction: a meta-analysis. Paper presented at the annual meeting of the American Educational Research Association, New York, april 1996.

Ben-Chaim, D., \& Zoller, U. (2001). Self-perception versus students' perception of teacher personal style in college Science and Mathematics courses. Research in Science Education, 31, 437-454.

Brekelmans, M. (1989). Interpersonal teacher behaviour in the classroom.[In Dutch]. Utrecht: W.C.C.

Brekelmans, M., Brok, P. den, Bergen, T., \& Wubbels, T. (2004). Exploring students' perceptions of their teachers' interpersonal communication style. Paper presented at the Annual Meeting of the American Educational Research Association, San Diego, April 12-16.

Brekelmans, M., Brok, P. den, Wubbels, T., \& Tartwijk, J. van (in press). An interpersonal perspective on teacher behaviour in the classroom. Accepted for publication in $\mathrm{C}$. Columbus (Ed.), Issues in teaching and teacher education (vol. 1). New York: Nova Science Publishers.

Brekelmans, M., Holvast, A., \& van Tartwijk, J. (1993). Changes in teacher communication styles during the professional career. Journal of Classroom Interaction, 27, 1322.

Brekelmans, M., Levy, J., \& Rodriguez, R. (1993). A typology of teacher communication style. In T. Wubbels \& J. Levy (Eds.), Do you know what you look like? (pp.46-55). London: The Falmer Press.

Brekelmans, M., Sleegers, P., \& Fraser, B. (2000). Teaching for active learning. In R.J. Simons, J. van der Linden \& T. Duffy (Eds.), New learning (pp.227-242 ). Dordrecht: Kluwer Academic Publishers.

Brekelmans, M., \& Wubbels, T. (1991). Student and teacher perceptions of interpersonal teacher behavior: A Dutch perspective. The Study of Learning Environments, 5, 19-30. 
Brekelmans, M., Wubbels, Th., \& den Brok, P. (2002). Teacher experience and the teacher-student relationship in the classroom environment. In S. C. Goh \& M. S. Khine (Eds.), Studies in educational learning environments: an international perspective (pp.73-100).

Singapore: World Scientific.

Brekelmans, M., Wubbels, Th. \& Créton, H.A. (1990) A study of student perceptions of physics teacher behavior, Journal of Research in Science Teaching, 27, 335-350.

Brok, P den. (2001). Teaching and student outcomes. A study on teachers' thoughts and actions from an interpersonal and a learning activities perspective. Utrecht: W.C.C.

Brok, P. den, Bergen, T., \& Stahl, R. (2002). Students' perceptions of teacher regulatory behaviors during learning activities. Paper presented at the annual meeting of the American Educational Research Association, New Orleans.

Brok, P. den, Brekelmans, M., \& Wubbels, T. (in press). Interpersonal teacher behaviour and student outcomes. Manuscript accepted for publication in School Effectiveness and School Improvement.

Brok, P. J., den Levy, J., Rodriguez, R., \& Wubbels, Th. (2002). Perceptions of AsianAmerican and Hispanic-American teachers and their students on interpersonal communication style. Teaching and Teacher Education, 18, 447-467.

Brok, P. den, Levy, J., Wubbels, Th., \& Rodriguez, M. (2003). Cultural influences on students' perceptions of videotaped lessons. International Journal of Intercultural Relations, 27, 355-374.

Brok, P. den, Fisher, D., Brekelmans, M., Rickards, T., Wubbels, Th., Levy, J., \& Waldrip, B. (2003, April). Students' perceptions of secondary teachers' interpersonal style in six countries: a study on the validity of the Questionnaire on Teacher Interaction. Paper presented at the annual meeting of the American Educational Research Association, Chicago. ERIC document: ED475164.

Brophy, J. E., \& Good, T. L. (1986). Teacher behaviour and student achievement. In M. C. Wittrock (Ed.), Handbook of research on teaching (3rd Ed.) (pp. 328-375). New York: MacMillan.

Brown, R. (1965). Social psychology. London: Collier-McMillan.

Corcoran, E. (1981) Transition shock: the beginning teacher paradox. Journal of Teacher Education, 32, 19-23

Creemers, B. P. M. (1994). The effective classroom. London: Cassell.

Créton, H. A. \& Wubbels, Th. (1984). Discipline problems with beginning teachers. [In Dutch]. Utrecht: W.C.C. 
Derksen, K. (1994). Between taking over and activating instruction. [In Dutch]. Masters thesis. Nijmegen: Vakgroep Onderwijskunde.

Derksen, K. (1995, August). Activating instruction: the effects of a teacher-training programme. Paper presented at the $6^{\text {th }}$ conference of the European Association for Research on Learning and Instruction, Nijmegen.

Doyle, W. (1986). Classroom organization and management. In M.C. Wittrock (Ed.), Handbook of Research on Teaching (pp. 392-431). New York: Macmillan.

Dunkin M. \& Biddle, B. (1974). The study of teaching. New York: Holt, Rinehart \& Winston.

Evans, H. (1998). A study on students' cultural background and teacher-student interpersonal behaviour in Secondary Science classrooms in Australia. Unpublished doctoral dissertation. Perth: Curtin University of Technology.

Festinger, L. (1957). A theory of cognitive dissonance. Evanston: Row Peterson.

Fisher, D., \& Cresswell, J. (1998), Actual and ideal principal interpersonal behaviour. Learning Environments Research, 1, 231-247.

Fisher, D. L., Henderson, D., \& Fraser, B. J. (1995). Interpersonal behaviour in senior high school biology classes. Research in Science Education, 25, 125-133.

Fisher, D., Fraser, B., \& Cresswell. J. (1995). Using the Questionnaire on Teacher Interaction in the professional development of teachers. Australian Journal of Teacher Education, 20, 8-18.

Fisher, D. L., Fraser, B. J. \& Wubbels, Th. (1992) Teacher communication style and school environment. Paper presented at the 1992 ECER conference, Enschede.

Fisher, D. L., Fraser, B. J., Wubbels, T., \& Brekelmans, M. (1993). Associations between school learning environment and teacher interpersonal behavior in the classroom. The Study of Learning Environments, 7, 32-41.

Fisher, D. L., \& Rickards, T. (1999). Teacher-student interpersonal behavior as perceived by science teachers and their students. Paper presented at the second international conference on Science, Mathematics and Technology Education, Taipei, Taiwan.

Foa, U. G. (1961). Convergence in the analysis of the structure of interpersonal behavior. Psychological Review, 68, 341-353.

Fraser, B. J. (1998), Science learning environments: assessment, effects and determinants, in B.J. Fraser, \& K.G. Tobin (Eds.), International handbook of science education, (pp. 527-564). London: Kluwer Academic Publishers.

Goh, S. C., \& Fraser, B. J. (1996). Validation of an elementary school version of the 
Questionnaire on Teacher Interaction. Psychological Reports, 79, 515-522.

Goh, S. \& Fraser, B.J. (2000). Teacher interpersonal teacher behaviour and elementary students' outcomes. Journal of Research in Childhood Education, 14, 216-231.

Harkin, J., \& Turner, G. (1997). Patterns of communication styles of teachers in English 16-19 education. Research in Post-Compulsory Education, 2, (3), 261-280.

Harper, R.G., Wiens, A.N. \& Matarazzo, J. D. (1978). Nonverbal communication: The state of the art. New York: John Wiley \& Sons.

Henderson, D. G. (1995). A study of the classroom and laboratory environments and student attitude and achievement in senior Secondary Biology classes. Unpublished doctoral dissertation. Perth: Curtin University of Technology.

Hockley, M., \& Harkin, J. (2000), Communicating with students with learning difficulties in further education. Educational Action Research, 8 (2), 341-360.

Huberman, M. (1993). Steps toward a developmental model of the teaching career. In L. Kremer-Hayon, H.C. Vonk \& R. Fessler (Eds), Teacher professional development: a multiple perspective approach (pp. 93-118). Amsterdam: Swets \& Zeitlinger.

Kounin J. S. (1970). Discipline and group management in classrooms. New York: Holt, Rinehart \& Winston.

Kremer-Hayon, L. \& Wubbels, Th. (1993a). Supervisors' interpersonal behavior and student teachers' satisfaction. In Wubbels, T., \& Levy, J. (Eds.). Do you know what you look like? (pp. 123-135) London: Falmer Press.

Kremer-Hayon, L. \& Wubbels, Th. (1993b). Principals' interpersonal behavior and teachers' satisfaction. In Wubbels, T., \& Levy, J. (Eds.). Do you know what you look like? (pp. 113-122) London: Falmer Press.

La France, M., \& Mayo, C. (1978). Moving bodies : nonverbal communication in social relationships. Monterey: Brooks/Cole Publishing Company.

Lapointe, J. M. (2003). Teacher-Student Conflict and Misbehavior: Toward a Model of the Extended Symmetrical Escalation. Journal of Classroom Interaction, 38, (2), 11-19.

Leary, T. (1957). An interpersonal diagnosis of personality. New York: Ronald Press Company.

Lee, O. (1995). Subject matter knowledge, classroom management, and instructional practices in middle school science classrooms. Research in Science Teaching, 32, 423-440.

Levy, J., Brok, P. den., Wubbels, Th., \& Brekelmans, M. (2003). Significant variables in students' perceptions of teacher interpersonal communication styles. Learning Environments Research, 6, 5-36. 
Levy, J., Wubbels, Th., \& Brekelmans, M. (1992). Student and teacher characteristics and perceptions of teacher communication style. Journal of Classroom Interaction, 27, 23-29.

Levy, J., Wubbels, T., Brekelmans, M., \& Morganfield, B. (1997). Language and cultural factors in students' perceptions of teacher communication style. International Journal of Intercultural Relations, 21, 29-56.

Lonner, W. J. (1980). The search for psychological universals. In H.C. Triandis \& W.W. Lambert (Eds.). Handbook of cross cultural psychology. (vol.1) pp. 143-204. Boston: Allyn and Bacon.

Marsh, H.W. (1982). Validity of students' evaluations of college teaching: A multitraitmultimethod analysis. Journal of Educational Psychology, 74, 264-279.

Marshall, H. H., \& Weinstein, R. S. (1986). Classroom context of student-perceived differential teacher treatment. Journal of Educational Psychology, 78 (6), 707-754.

Morine-Dershimer, G. (1986). Introduction: perspectives on a teaching episode. Teaching and Teacher Education, 2, 299-300.

Muller Fohrbrodt, G. (1978) Der Praxisschock bij Jungen Lehrern. (The reality shock with young teachers) Stuttgart: Klett.

Rawnsley, D. G. (1997). Associations between classroom learning environments, teacher interpersonal behaviour and student outcomes in Secondary Mathematics classrooms.

Unpublished doctoral dissertation. Perth: Curtin University of Technology.

Rickards, T., \& Fisher, D. L. (2000). Three perspectives on perceptions of teacherstudent interaction: a seed for change in science teaching. Paper presented at the annual meeting of the National Association for Research in Science Teaching, New Orleans.

Robertson, J. (2002). The Boss, the Manager and the Leader: approaches to dealing with disruption. In B. Rogers (Ed.) Teacher leadership and behaviour management (pp. 20-39) London: Sage.

Scott, R., Fisher, D., \& Brok, P. den (2003, August). Specialist Science teachers' classroom behaviors in 12 primary schools. Paper presented at the annual conference of the European Science Education Research Association, Noordwijkerhout.

Segall, M. H., Dasen, P. R., Berry, J. W., \& Poortinga, Y. H. (Eds.). (1990). Human behavior in global perspective: An introduction to cross-cultural psychology. New York: Pergamon.

Setz, W., Bergen, Th., van Amelsvoort, J., \& Lamberigts, R. (1993). Perceived and observed behaviour of teachers. [In Dutch] Nijmegen: Katholieke Universiteit Nijmegen/ITS.

Shavelson, R .J., Webb, N. W., \& Burstein L. (1986). Measurement of teaching. In: M. C. 
Wittrock, (Ed.), Handbook of research on teaching (third edition, 50-91). New York: Macmillan.

Shuell, T.J. (1996). Teaching and learning in a classroom context. In D.C. Berliner, \& R.C. Calfee (Eds.), Handbook of educational psychology (pp. 726-763). New York: MacMillan.

Slater, P.E. (1962). Parental behavior and the personality of the child. Journal of Genetical Psychology, 101, 53-68.

Soerjaningsih, W., Fraser, B. J., \& Aldridge, J. M. (2002). Instructor-student interpersonal behavior and student outcomes at the university level in Indonesia. Paper presented at the annual meeting of the American Educational Research Association, april, New Orleans.

Somers, T., Brekelmans, M., \& Wubbels, Th. (1997, August). Development of student teachers on the teacher-student relationship in the classroom. Paper presented at the $7^{\text {th }}$ conference of the European Association for Research on Learning and Instruction, Athens.

Strack, S. (1996). Special series: Interpersonal theory and the interpersonal circumplex: Timothy Leary's Legacy, Journal of Personality Assessment, 66, 211-307.

Tartwijk, J. van (1993). Sketches of teacher behavior: the interpersonal meaning of nonverbal teacher behavior in the classroom. [in Dutch] Utrecht: W.C.C.

Tartwijk, J. van, Brekelmans, M., Wubbels, T., Fisher, D. L., \& Fraser, B. J. (1998). Students perceptions of teacher interpersonal style: the front of the classroom as the teacher's stage. Teaching and Teacher Education, 14, 1-11.

Veenman, S. A. M. (1984). Perceived problems of beginning teachers. Review of Educational Research, 54, 143-178.

Watzlawick, P., Beavin, J. H., \& Jackson, D. (1967). The pragmatics of human communication. New York: Norton.

Weber, S., \& Mitchell, C. (1995). 'That's funny, you don't look like a teacher': interrogating images and identity in popular culture. London: The Falmer Press.

Wiggins, J. S., Philips, N., \& Trapnell, P. (1989), Circular reasoning about interpersonal behavior: evidence concerning some untested assumptions underlying diagnostic classification, Journal of Personality and Social Psychology, 56, 296-305.

Wubbels, T., \& Brekelmans, M. (1997). A comparison of student perceptions of Dutch Physics teachers' interpersonal behavior and their educational opinions in 1984 and 1993. Journal of Research in Science Teaching, 34, (5), 447-466.

Wubbels, T., Brekelmans, M., \& Hermans, J. (1987). Teacher behavior: an important aspect of the learning environment? The Study of Learning Environments, 3, 10-25.

Wubbels, Th., Brekelmans, M. \& Hooymayers H. P. (1992). Do teacher ideals distort the self-reports of their interpersonal behavior? Teaching and Teacher Education, 8, 47-58. 
Wubbels, Th., Brekelmans, M. \& Hooymayers H. P. (1993). Comparison of Teachers' and Students' Perceptions of Interpersonal Behavior. In Wubbels, T., \& Levy, J. (Eds.). Do you know what you look like? (pp. 64-80) London: Falmer Press.

Wubbels, Th., Créton, H., \& Holvast, A. J. C. D. (1988). Undesirable classroom situations. Interchange, 19, 25-40.

Wubbels, Th., Créton, H. A. \& Hooymayers, H.P. (1985) Discipline problems of beginning teachers, interactional teacher behavior mapped out. Abstracted in Resources in Education, 20, 12, p. 153, ERIC document 260040.

Wubbels, T., Créton, H.A, \& Hooymayers, H.P. (1987). A school-based teacher induction programme. European Journal of Teacher Education, 10, 81-94.

Wubbels, T., \& Levy, J. (1991). A comparison of interpersonal behavior of Dutch and American teachers. International Journal of Intercultural Relations, 15, 1-18.

Wubbels, T., \& Levy, J. (1993). Do you know what you look like? London: Falmer Press.

Yuen, H. K. (1999). Communication styles of tertiary teachers. In J. James (Ed.), Quality in teaching and learning in higher education (pp.3-8). Hong Kong: Hong Kong Polytechnic University. 


\section{Captions of figures}

Figure 1. Two-dimensional co-ordinate system of the Model for Interpersonal Teacher Behavior Figure 2. Model for Interpersonal Teacher Behavior

Figure 3. Rating scales for observation of students' perceptions at the message and interaction level

Figure 4. Main points of the eight types of patterns of interpersonal relationships.

Figure 5. (Estimated) Proximity scores in the first eight years of the teaching career (longitudinal study).

Figure 6. Mean Influence (DS) scores by experience level (cross-sectional study).

Figure 7. Mean Proximity (CO) scores by experience level (cross-sectional study).

Figure 8. Dimension scores and the use of voice.

Figure 9. Dimension scores and facial expression.

Figure 10. Combinations of behavior with a relatively high (left) and low (right) influence perception. In the left position the teacher is relatively far from the student, with his or her head in upright position, scanning and talking long in a rather low voice. In the right position the teacher is close to the students with his or her head down so that his or her facial expression cannot be seen.

Figure 11. Interpersonal profiles of teachers with relatively high and low student outcomes Figure 12. Interpersonal profiles of teachers with relatively high and low student attitudes Figure 13. Teacher ideal, self-report and students' perceptions of one teacher. The self-report occupies a position between students' perceptions and ideal.

Figure 14. Teacher ideal, self-report and students' perceptions of one teacher. The self-report is further away from the ideal than the students' perceptions. 


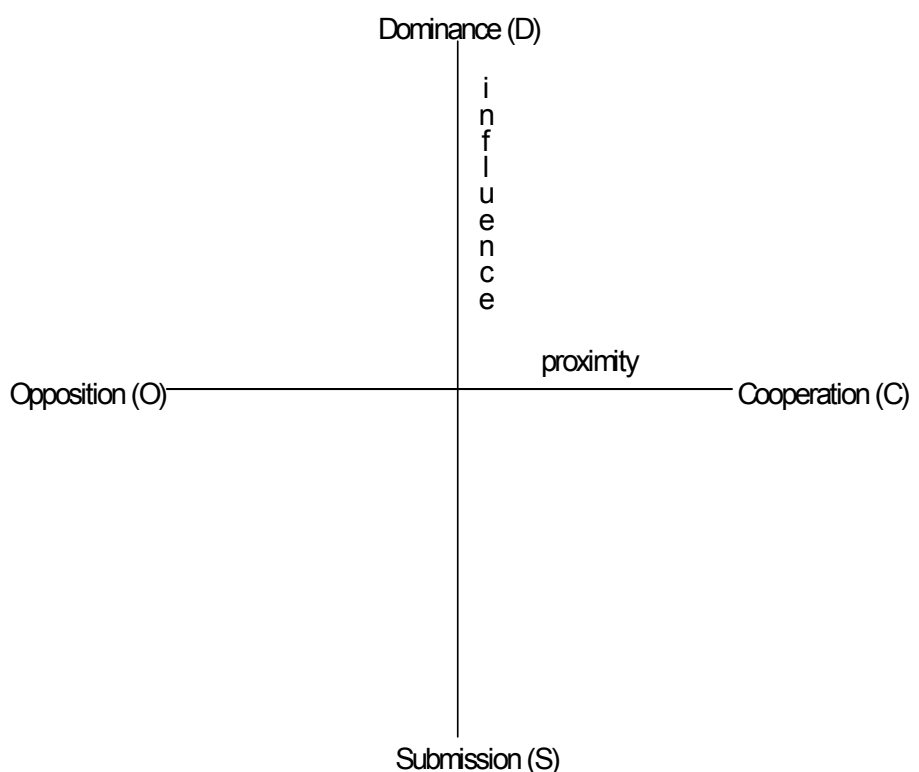

Figure 1. 


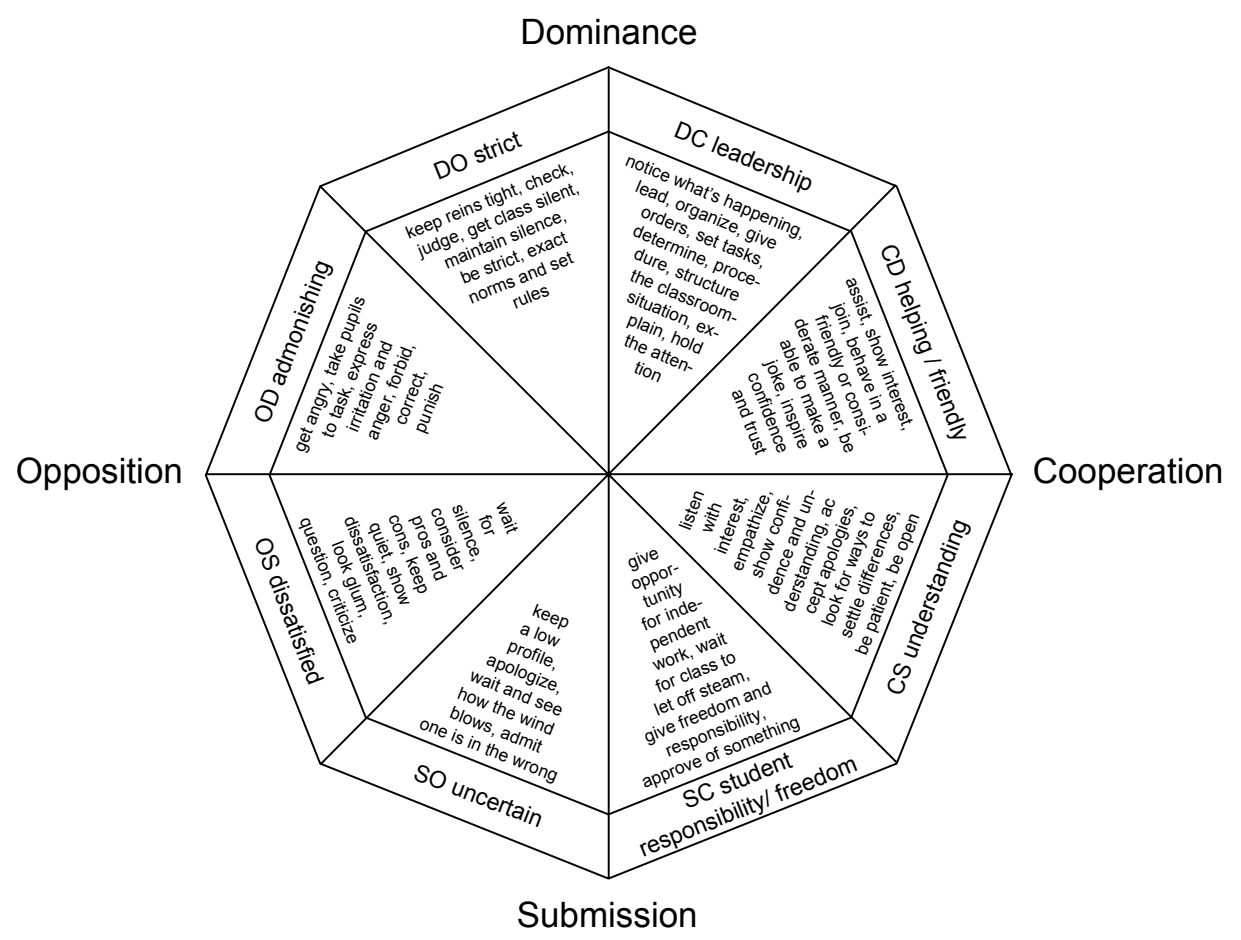

Figure 2. 


\section{Dominance (D)}

The teacher determines the 5--4--3--2--1 students' activities.

\section{Co-operation (C)}

The teacher shows approval 5--4--3--2--1 of the students and their behavior.

Figure 3.

\section{Submission (S)}

The students can determine their own activities.

\section{Opposition (O)}

The teacher shows disapproval of the students and their behavior. 


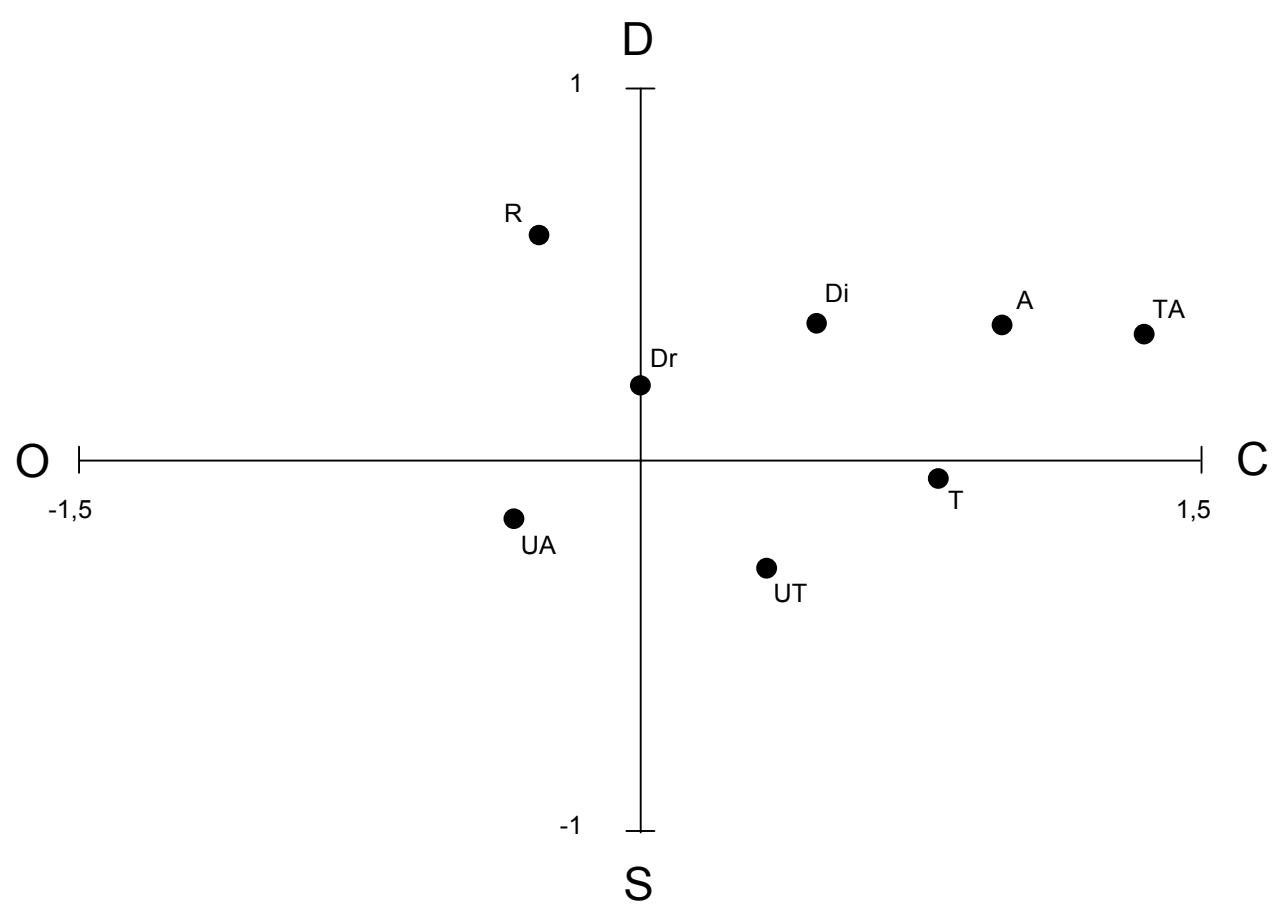

$A=$ Authoritative, $D i=$ Directive, $D r=$ Drudging,$T=$ Tolerant,$R=$ Repressive, $T A=$ Tolerant/Authoritative, $U A=$ Uncertain/Aggressive, $U T=U n c e r t a i n / T o l e r a n t$

Figure 4. 


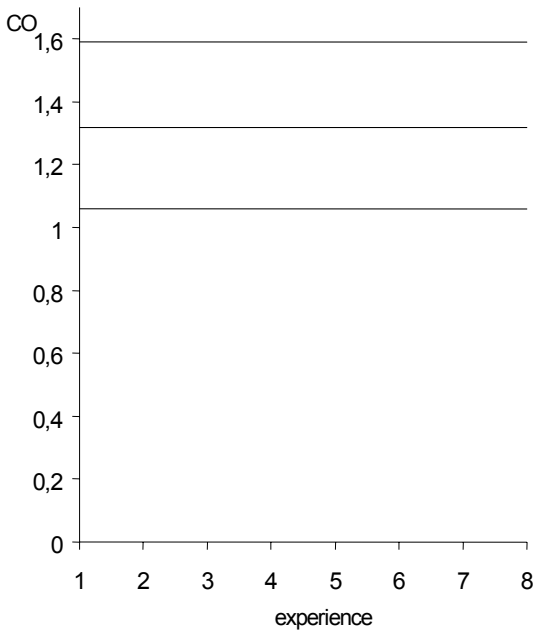

Ideal perceptions of teachers

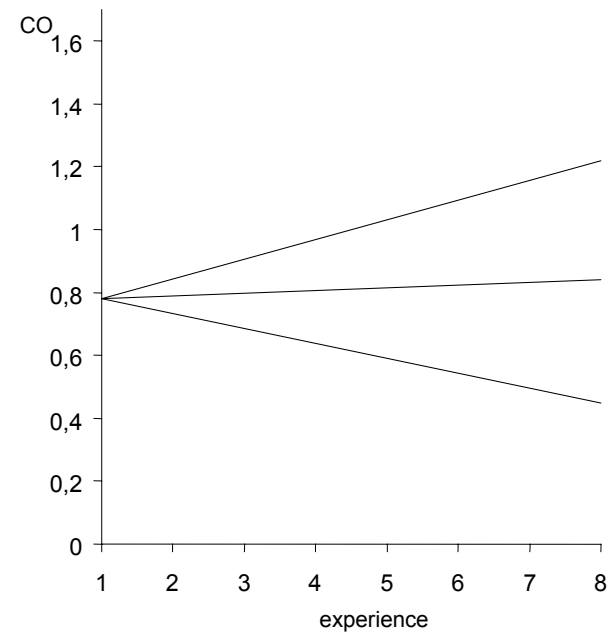

Self-perceptions of teachers

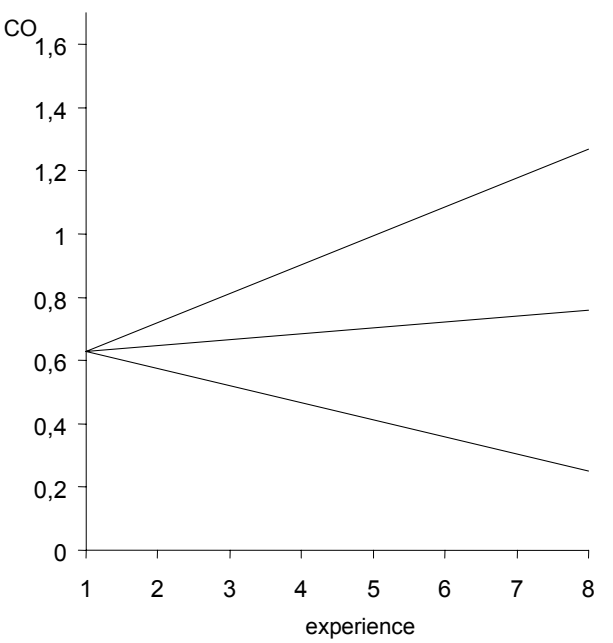

Students' perceptions of teachers

Figure 5. 
DS

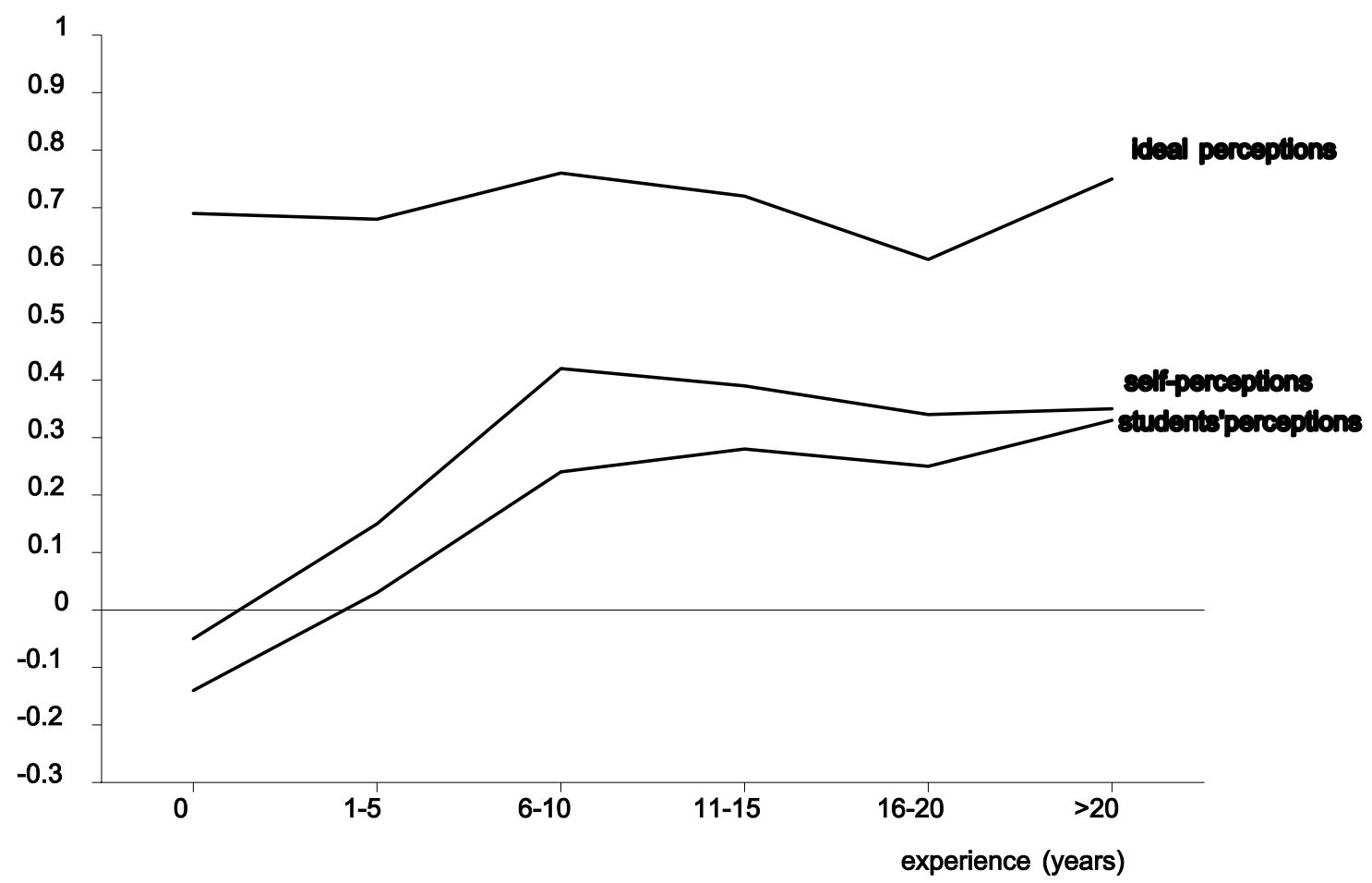

Figure 6. 


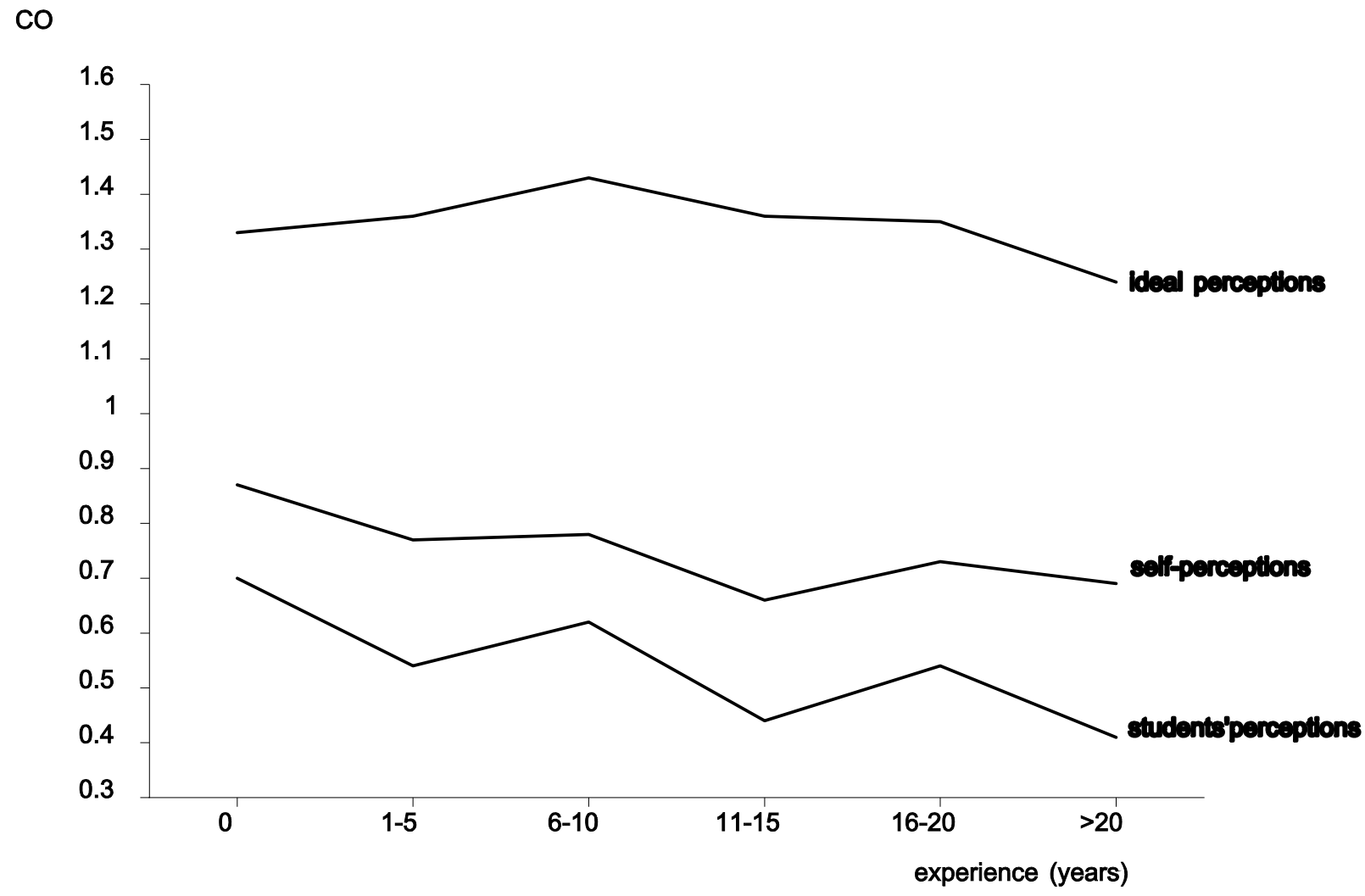

Figure 7. 
Voice

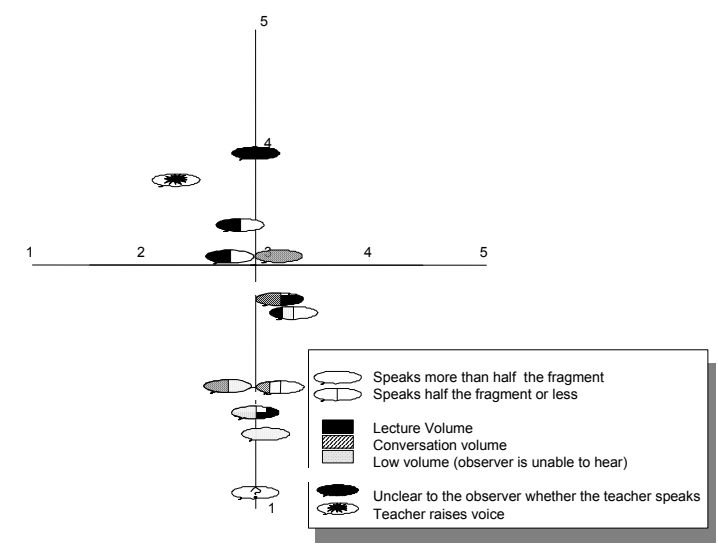

The relation between the Voice channel and the DS ratings shows that the longer teachers speak using a lecturing volume, the more they are perceived as dominant and the longer teachers speak in such a way that they cannot be heard by the observer, the more the teachers' behaviour is perceived as submissive.

For the $\mathrm{CO}$ ratings, whether teachers raise their Voice is the most important distinctive feature.

Figure 8 . 
Face

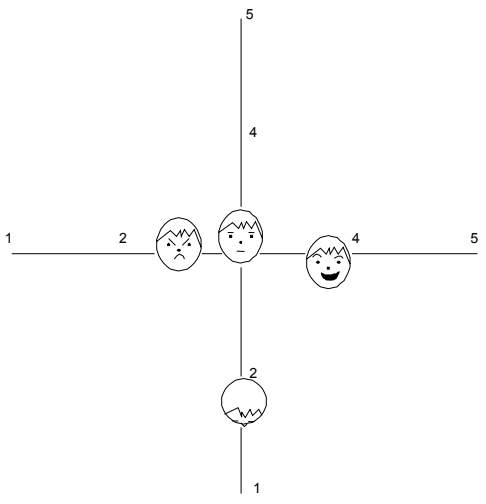

For the DS ratings, the visibility of the face for the students was the most important factor. Not surprising if compared with the importance of an upright head position for a rating as relatively dominant.

The most important facial expression for the $\mathrm{CO}$ ratings were laughing, neutral or angry facial expressions.

Figure 9. 

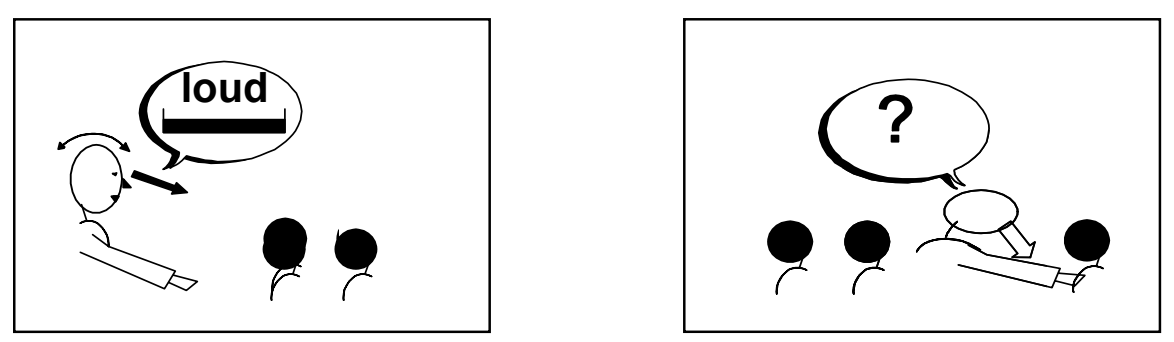

Figure 10. 


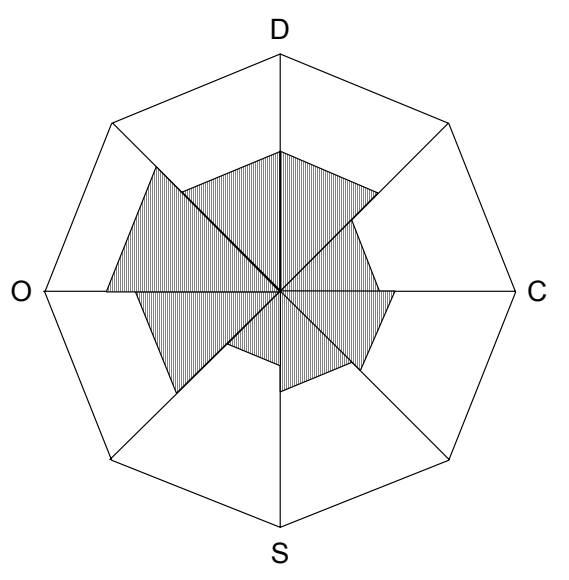

High student achievement

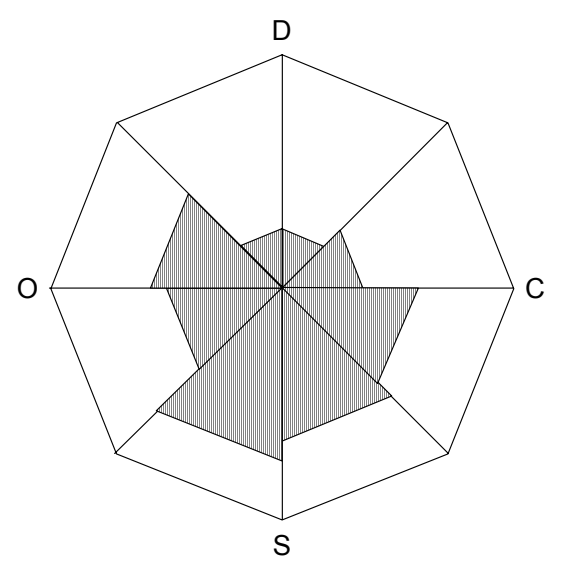

Low student achievement

Figure 11 


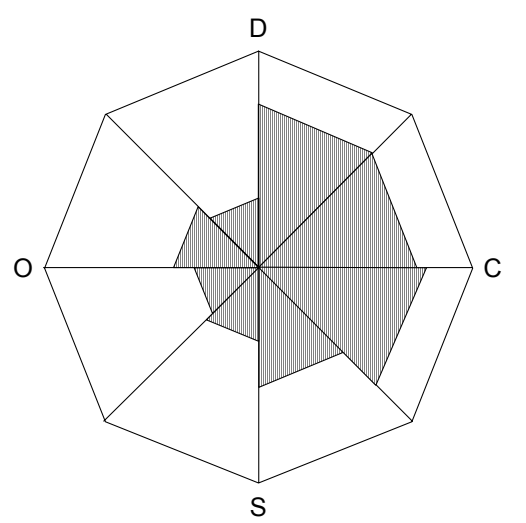

High student attitudes

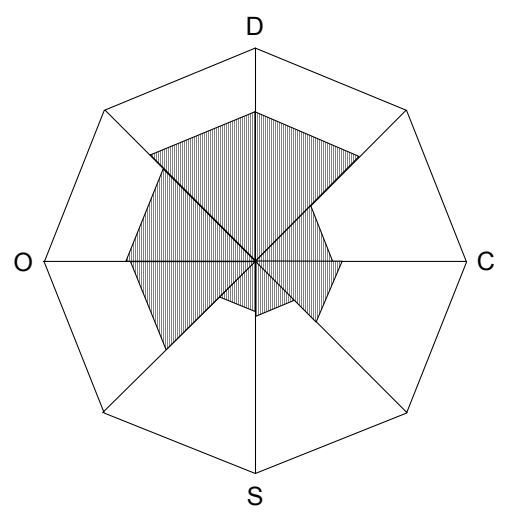

Low student attitudes

Figure 12 


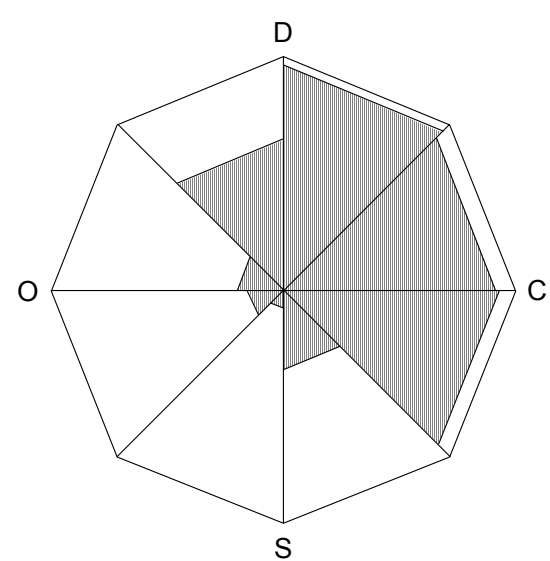

Teacher ideal

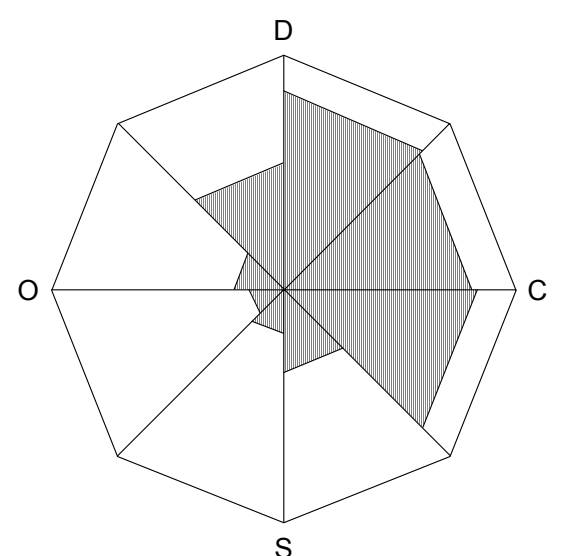

Teacher self perception

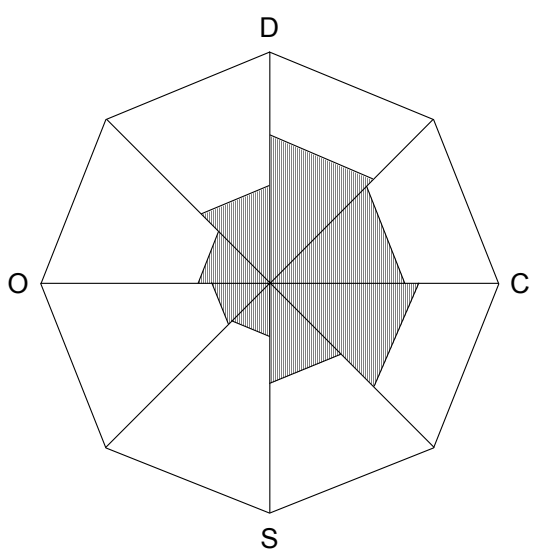

Students' perception

Wishful thinking

Figure 13 


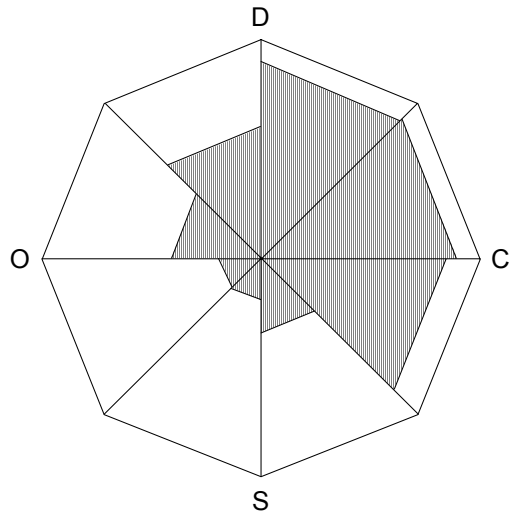

Teacher ideal

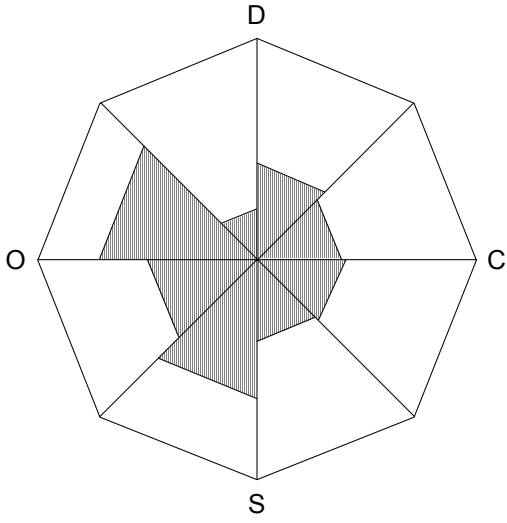

Teacher self perception

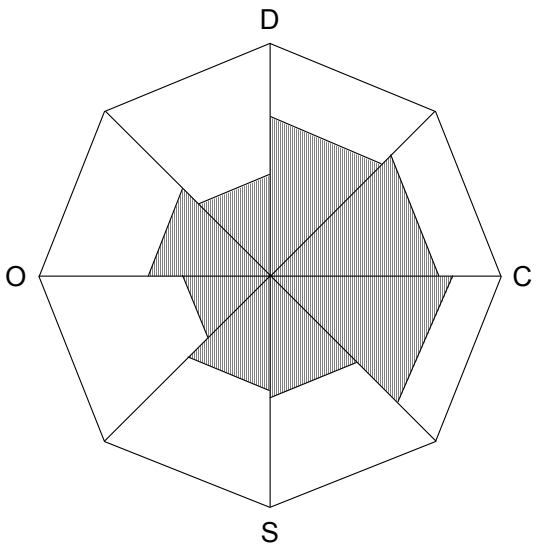

Students' perception

Protection against disappointment

Figure 14. 